Check for updates

Cite this: J. Mater. Chem. C, 2020 8, 11805

Received 26th April 2020

Accepted 1st July 2020

DOI: $10.1039 / \mathrm{dOtc02038a}$

rsc.li/materials-c

\title{
Investigating the structure-function relationship in triple cation perovskite nanocrystals for light-emitting diode applications $\$$
}

\author{
Parth Vashishtha, D *a Sjoerd A. Veldhuis, ${ }^{\text {b }}$ Sai S. H. Dintakurti, ${ }^{\text {acd }}$ Nicole L. Kelly, \\ Benjamin E. Griffith, (D) ac Alasdair A. M. Brown, (D) be Mohammed S. Ansari, ${ }^{\text {a }}$ \\ Annalisa Bruno, (D) ${ }^{\mathrm{b}}$ Nripan Mathews, (D) ${ }^{\mathrm{ab}}$ Yanan Fang, (D) ${ }^{\mathrm{a}}$ Tim White, ${ }^{\mathrm{a}}$ \\ Subodh G. Mhaisalkar (iD *ab and John V. Hanna (iD *ac
}

\begin{abstract}
Organic metal halide perovskite nanocrystals are promising candidates for light-emitting diodes due to their narrow emission bandwidth, high photoluminescence quantum yield (PLQY), and color tunability. Nevertheless, these systems suffer from thermal instability, phase impurities, and a sensitivity to processing techniques. This study reports the first synthesis of novel Cs-containing triple cation perovskite nanocrystals with nominal stoichiometry $\mathrm{Cs}_{x}\left(\mathrm{MA}_{0.17} \mathrm{FA}_{0.83}\right)_{1-x} \mathrm{PbBr}_{3}(x=0-0.15)$. The effect of $\mathrm{Cs}^{+}$cation incorporation is thoroughly investigated using diffraction, microscopy and solid state MAS NMR techniques. The solid state ${ }^{133} \mathrm{Cs}$ MAS NMR results reveals the distribution of the $\mathrm{Cs}^{+}$cations is highly concentration and particle size dependent, with maximized surface/subsurface $\mathrm{Cs}^{+}$concentrations being achieved with the smaller $5 \mathrm{~mol} \%$ Cs system. These characteristics directly correlate improved surface passivation and environmental stability of the triple cation system. These triple cation nanocrystals exhibit a maximum photoluminescence quantum yield of $\sim 93 \%$ which upon translation to nanocrystalline LED devices delivers a maximum EQE of $7.4 \%\left(30 \mathrm{~cd} \mathrm{~A}^{-1}\right)$ corresponding to a power efficiency of $34.87 \mathrm{Im} \mathrm{W}^{-1}$. This performance represents a marked improvement compared to $\mathrm{CsPbBr}_{3}$ nanocrystals ( $\mathrm{PL}$ quantum yield 50\%; maximum EQE of $\left.2.5 \%\left(7.2 \mathrm{~cd} \mathrm{~A}^{-1}\right)\right)$ fabricated under similar conditions.
\end{abstract}

\footnotetext{
${ }^{a}$ School of Materials Science and Engineering, Nanyang Technological University (NTU), 50 Nanyang Avenue, Singapore 639798, Singapore. E-mail: pvashishtha@ntu.edu.sg, subodh@ntu.edu.sg

${ }^{b}$ Energy Research Institute@NTU (ERI@N), Research Techno Plaza,X-Frontier Block, Level 5, 50 Nanyang Drive, Singapore 637553, Singapore

${ }^{c}$ Department of Physics, University of Warwick, Gibbet Hill Rd., Coventry CV4 7AL, UK. E-mail: j.v.hanna@warwick.ac.uk

${ }^{d}$ Interdisciplinary Graduate School, Nanyang Technological University (NTU), 50 Nanyang Avenue, Singapore 639798, Singapore

${ }^{e}$ School of Engineering, Faculty of Engineering and Physical Sciences, University of Southampton, Southampton SO17 1BJ, UK

$\dagger$ The experimental data for this study are provided as a supporting dataset from WRAP, the Warwick Research Archive Portal at https://wrap.warwick.ac.uk/ 134281 .

\# Electronic supplementary information (ESI) available: Experimental details of the device fabrication and materials characterization including XRD, TEM, NMR, UV-vis, and PL methodologies. Also shown are TEM micrographs for size and lattice spacing estimation, powder XRD, FTIR, ${ }^{133} \mathrm{Cs} T_{1}$ data acquired from MAS NMR, a graph describing the relationship between $\mathrm{H}-\mathrm{H}$ distance $v$ s. the number of protons in $\mathrm{MAPbBr}_{3}$ system, 2D homonuclear ${ }^{1} \mathrm{H}^{-1} \mathrm{H}$ MAS NMR data from triple cation and $\mathrm{CsPBBr}_{3}$ systems, graphs showing the optoelectronic properties of the $\mathrm{CsPbBr}_{3}$ nanocrystals, PESA measurements, and remaining device characterisation for triple cation systems including the effect of crown ether, a table outlining the precursor concentrations, a table for elemental analysis using EDXS, and a table describing the effect of crown LED performance. See DOI: $10.1039 /$ dotc02038a
}

\section{Introduction}

Nanocrystals provide several advantages for optoelectronic applications as compared to bulk materials. ${ }^{1-4}$ They have higher photoluminescence quantum yields (PLQY), narrower emission bandwidth, higher stability, size tuneable optical properties, and the capability for surface functionalisation., ${ }^{3,5-11}$ Nanocrystal or quantum dot based light emitting diodes (QLEDs) are amongst the best performing LEDs, owing to impressive color rendering, high brightness and higher thermal stability. ${ }^{5,12,13}$ In the past two decades, several advancements have been made for variety of quantum dots, leading to the fabrication of electrically driven QLEDs with emission throughout the visible range. ${ }^{5,13,14}$ Currently, state-of-the-art QLEDs use CdSe based core-shell quantum dots as an active layer. ${ }^{15}$ However, over the last few years, perovskite materials have emerged as promising competitors for optoelectronic applications.

Organic-inorganic metal halide perovskite materials have demonstrated attractive properties for applications such as solar cells, LEDs and photodetectors. They have the potential for very cost-effective fabrication, due to both the low precursor material costs and their suitability for scalable, high-throughput, 
solution-processing techniques. Moreover, the composition tuneability of the perovskite structure offers a powerful approach to optimize the material properties for specific applications. ${ }^{16,17}$ Since their discovery fifteen years ago, the power conversion efficiency (PCE) of perovskite-based solar cells has improved enormously from $3.6 \%$ to $25.2 \% .^{18-22}$ Although methylammonium (MA), formamidinium (FA) and mixed MA/FA based lead halide perovskite solar cell materials demonstrate reasonably high efficiencies, they are very sensitive to processing techniques as a result of thermal and structural instability. ${ }^{23-26}$ Additionally, MA/FA based perovskite films have revealed difficulties with phase impurity and significant defects and disorder influencing the crystalline framework. ${ }^{23,27}$ The addition of $\mathrm{Cs}^{+}$as a third cation into the FA/MA perovskite films has provided a viable solution to these problems as triple cation films exhibit greater stability and higher purity. ${ }^{23,27,28}$ Furthermore, triple cation perovskites show less sensitivity to processing conditions, thus offering a higher degree of device reproducibility. ${ }^{28-30}$ As a result, triple cation perovskite devices have shown higher power conversion efficiency in perovskite solar cells. ${ }^{23,27,30}$

In addition to solar cell devices, perovskites have also attracted significant attention for LED applications. Their tunable emission wavelength has facilitated LEDs of external quantum efficiency (EQE) $>20 \%$ for green, red and near-IR light. ${ }^{31-34}$ In order to be viable for LED applications, a material should exhibit high exciton binding energy, narrow PL emission linewidth, and high PLQY. ${ }^{35,36}$ Hence, prior research has focused on perovskite nanocrystal systems and low dimensional perovskite materials where charge confinement greatly enhances these vital properties. ${ }^{31,35,37-40}$ Similar to perovskite solar cells, mixed cation systems have proven very useful for LED production. Zhang et al. reported mixed cation $\mathrm{FA}_{(1-x)} \mathrm{Cs}_{x} \mathrm{PbBr}_{3}$ perovskite LEDs and found a significant improvement in EQE from $0.82 \%$ to $1.82 \%$ upon introducing Cs cations, ${ }^{41}$ while $\mathrm{Xu}$ et al. reported the perovskite LEDs based on mixed cation $\mathrm{FA}_{x} \mathrm{MA}_{(1-x)} \mathrm{PbBr}_{3}$ quantum dots. ${ }^{42}$ The influence of cation mixing was elucidated by Borriello et al. who used computational studies to demonstrate that varying distortion of the crystal structure with different A site cations alters the electronic properties of the perovskite. ${ }^{43}$ This trend encourages research into the formulation of mixed cation based perovskite materials for the next generation of LEDs. Although Kim et al. reported the first LEDs made from triple cation bulk perovskites, achieving EQEs of $1.7 \%, 7.3 \%$ and $9.23 \%$ for blue, green, and near infrared emission, respectively, ${ }^{44}$ LEDs from triple cation perovskite nanocrystal systems have not yet been reported.

In this work, novel triple cation perovskite nanocrystals of nominal stoichiometry $\mathrm{Cs}_{x}\left(\mathrm{FA}_{0.83} \mathrm{MA}_{0.17}\right)_{1-x} \mathrm{PbBr}_{3}(x=0-0.15)$ were synthesized using the room temperature ligand-assisted reprecipitation (LARP) method. ${ }^{35,45-49}$ Octylamine and oleic acid were introduced as surface passivation agents, while dibenzo-21-crown-7-ether effectively solvated the $\mathrm{Cs}^{+}$cations (from solid CsBr) in DMF solutions. Nanocrystalline systems of varying $\mathrm{Cs}$ incorporation have been characterized by HR-TEM, XRD and an extensive multinuclear solid state MAS NMR study to evaluate the long-range order and short-range disorder that characterizes the structural heterogeneity and structurefunction aspects of these systems. The photoluminescence quantum yield (PLQY) and external quantum efficiency (EQE) characterizing the optoelectronic performance of these materials, and their potential for LED device fabrication, were also assessed.

\section{Results and discussion}

\section{Structural characterization}

TEM and XRD analyses. Monodispersed spherical triple cation nanocrystals were synthesized with $0,5,10$ and $15 \mathrm{~mol} \%$ of the $\mathrm{Cs}^{+}$cation incorporated within the triple cation inventory. Fig. 1(a-e) and Fig. S1 (ESI ) show the high resolution transmission electron micrographs (HR-TEM) of the as-synthesized samples, together with the average particle size data and the size distributions represented in histogram form. The nanocrystal shape is predominantly spherical, with the average particle diameter $(\sim 5-8 \mathrm{~nm})$ observed to increase monotonically with increasing Cs content. These particles were persistent under $200 \mathrm{keV}$ electron beam exposure for up to $\sim 40-45 \mathrm{~s}$. This increasing particle size characteristic is attributed to faster nanoparticle growth with elevated Cs incorporation. Although the size increase is modest, it exerts a marked influence on the distribution of the $\mathrm{Cs}^{+}$cation throughout the nanocrystal structure composition (see the ${ }^{133}$ Cs MAS NMR data below, vide infra). These HR-TEM data showed that, irrespective of the $\mathrm{Cs}^{+}$cation concentration, a high degree of long-range order within the $\mathrm{PbBr}_{6}{ }^{4-}$ framework was maintained (see Fig. 1a-h).

These characteristics contrast with the morphological behavior of $\mathrm{CsPbr}_{3}$ nanoparticles that form highly crystalline nanocubes (average edge $\sim 11 \mathrm{~nm}$ ). As shown in Fig. $2 \mathrm{a}$ and b, this system readily exhibits lattice fringes indicating a $d$ spacing of $5.8 \AA$, in agreement with previous studies. ${ }^{32,50}$ However, the lower and higher magnification HR-TEM images in Fig. 2c-e show decomposition under shorter electron beam exposure of $\sim 15 \mathrm{~s}$ (i.e. in comparison to similar TEM beam conditions used to study the triple cation systems), consequently inducing a heavily disordered material comprised of various particle shapes and ranges of dimensions.

A powder X-ray diffraction study of the triple cation nanocrystal series confirmed the formation of $P m \overline{3} m$ cubic perovskite materials. ${ }^{51,52}$ While XRD patterns from drop-cast nanocrystal suspensions on zero background substrate holders can exhibit some texture leading to modification of the measured diffraction intensities (see Fig. 1f and g), ${ }^{51,52}$ those from these nanocrystal precipitates showed no preferred orientation (see Fig. S2a, ESI $\neq$ ). As evidenced by the HR-TEM image of Fig. 1e for the $5 \mathrm{~mol} \% \mathrm{Cs}$ sample, the nanocrystal lattices were highly ordered as the $\langle 200\rangle_{\text {cubic }}$ lattice fringes are visible, with the superimposed FFT match of the $\langle 200\rangle$ plane obtained from the XRD data (see Fig. 1f-h) corresponding to a $d$ spacing of $\sim 2.97 \AA$. As the X-ray scattering power and effective ionic radius of the $\mathrm{Cs}^{+}, \mathrm{FA}^{+}$and $\mathrm{MA}^{+}$cations both progressively decrease, Fig. 1f-i and Fig. S2b-d (ESI $\$$ ) demonstrate that there are systematic changes in unit cell edge and the relative intensity of $\langle 100\rangle /\langle 200\rangle$ with composition in accordance 


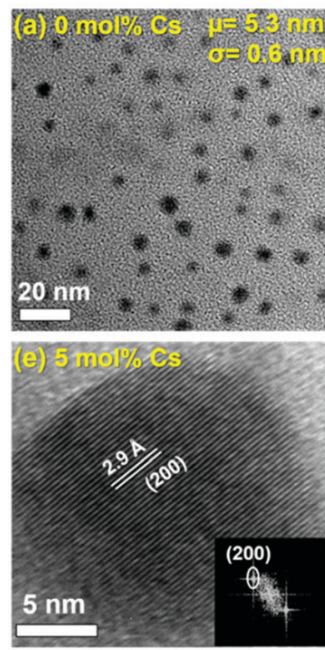

(h)

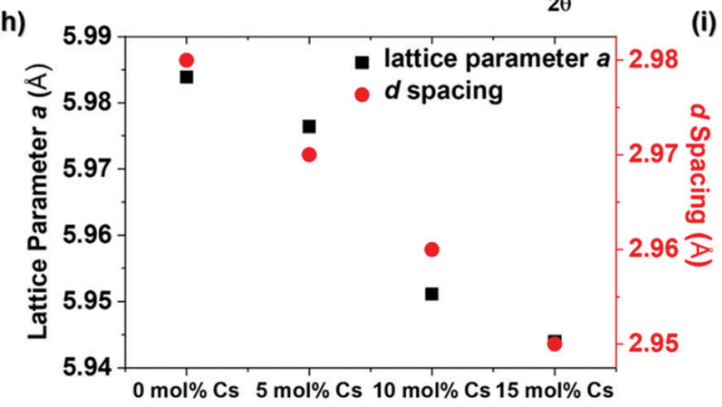

Composition

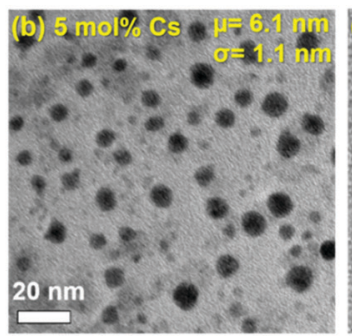

(f)

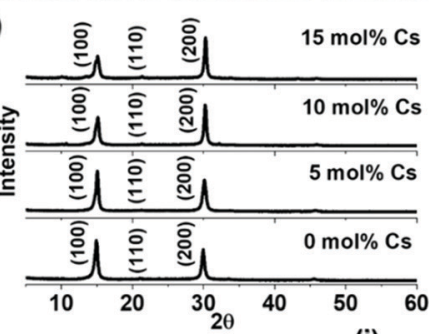

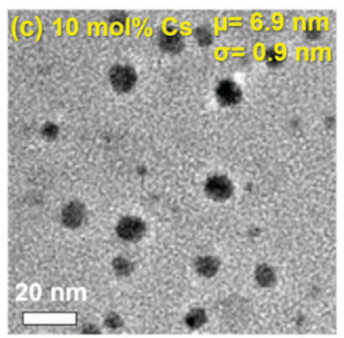

(g)
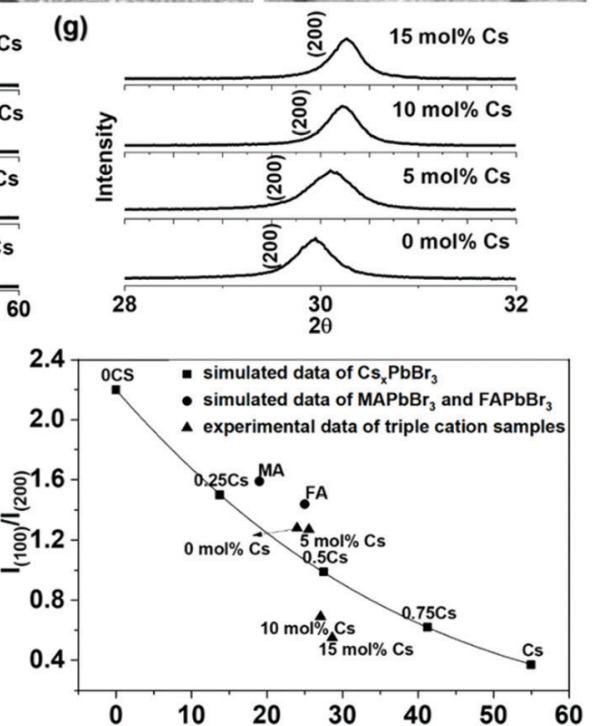

Average Atomic Number of Atoms at A site

Fig. 1 High resolution transmission electron microscopy (HR-TEM) images of nanocrystals supporting, (a) 0 mol\% Cs, (b) 5 mol\% Cs, (c) 10 mol\% Cs, and (d) $15 \mathrm{~mol} \% \mathrm{Cs}$. These nanocrystals were persistent under the beam for $\sim 45 \mathrm{~s}$. (e) Shows the imaging of the lattice planes in the 5 mol\% Cs preparation, while $(f)-(h)$ show the powder XRD data, the expansion of the $30^{\circ} 2 \theta$ region highlighting the peak shift in the (200) plane, and the change in the lattice parameter a with Cs incorporation, respectively. These XRD data pertaining to the $d$ spacing analysis are uncorrected for sample displacement, thus yielding the discrepancy between $d$ spacing and lattice parameter a data in (h). (i) Illustrates the relationship between the relative XRD peak intensities of $\langle 100\rangle$ vs. $\langle 200\rangle$ taken from (f) and the average atomic number of the A site cations. In addition, the simulations of the relative intensity I(100)//(200) vs. the average atomic number of the $\mathrm{A}$ site cations from the $\mathrm{CsPbBr}_{3}, \mathrm{MAPbBr}_{3}$, and $\mathrm{FAPbBr}_{3}$ systems are plotted for comparison.

with the nominal compositions. ${ }^{53,54}$ A continuous solid solution has been previously reported in microcrystalline triple cation perovskite thin films. ${ }^{23}$ The incorporation of FA and MA was further confirmed by FTIR of $\mathrm{Cs}_{0.05}\left(\mathrm{FA}_{0.83} \mathrm{MA}_{0.17}\right)_{0.95} \mathrm{PbBr}_{3}$ nanocrystals (see Fig. S3, ESI\$). TEM-EDXS corroborated that the Cs, $\mathrm{Pb}$ and $\mathrm{Br}$ molar ratios are in good agreement with the nominal starting precursor proportions (see Tables S1 and S2, ESI ). This analysis was coupled with further elemental analysis undertaken using solid state ${ }^{1} \mathrm{H}$ and ${ }^{13} \mathrm{C}$ MAS NMR studies (vide infra) to confirm the A-site $\mathrm{FA}^{+}$and $\mathrm{MA}^{+}$cation stoichiometry comprising the triple cation systems.

\section{Multinuclear solid state NMR - nanocrystal core}

The ${ }^{133} \mathrm{Cs}$ MAS NMR data for the bulk $\mathrm{CsPbBr}_{3}, \mathrm{CsPbBr}_{3}$ nanocrystal (average particle size $\sim 11 \mathrm{~nm}$ ) and the triple cation $\mathrm{Cs}_{x}\left(\mathrm{MA}_{0.17} \mathrm{FA}_{0.83}\right)_{1-x} \mathrm{PbBr}_{3}(x=0.05-0.15)$ nanocrystal series are shown in Fig. 3a and Fig. S4 (ESI\$), and summarised in Table 1. While the bulk orthorhombic $\mathrm{CsPbBr}_{3}$ phase is characterised by a single resonance at $\delta 117 \mathrm{ppm}$ and a long $T_{1}$ value of $\sim 103 \mathrm{~s}\left(B_{0}=14.1 \mathrm{~T}\right)$, the data for the $\mathrm{CsPbBr}_{3}$ nanocrystals indicates that more complex Cs speciation describes this system. Broader upfield signals at $\delta 109 \mathrm{ppm}$ and $\delta 95 \mathrm{ppm}$ assigned to $\mathrm{Cs}^{+}$cations residing in the sub-surface and surface nanocrystal layers, respectively, accompany the bulk $\mathrm{CsPbBr}_{3}$ resonance $(\delta 117 \mathrm{ppm})$ characterising the nanocrystal core. The layers experience increasing short-range disorder and structural strain associated with the cumulative loss of translational symmetry as these Cs positions approach the particle surface. As evidenced in Table 1, Fig. 3a and Fig. S4 (ESI ments are supported by the increasing ${ }^{133} \mathrm{Cs}$ linewidths and markedly reducing $T_{1}$ values that trend upfield (i.e. towards decreasing ${ }^{133} \mathrm{Cs}$ chemical shift) with increasing proximity of the $\mathrm{Cs}^{+}$cations to the nanocrystal surface. This effect is most acute for the surface Cs positions experiencing direct contact with the disordered and motional passivation layer stabilising the $\mathrm{CsPbBr}_{3}$ nanocrystal surface. Although ${ }^{133} \mathrm{Cs}(I=7 / 2)$ is a quadrupolar nucleus, the very small quadrupole moment $Q$ of $-0.343 \times$ $10^{-30} \mathrm{~m}^{2}$ affords the observation of resonances which are dominated by chemical shift dispersion induced by short-range disorder. These observations mirror the findings from previous ${ }^{195} \mathrm{Pt}$ and ${ }^{105}$ Pd NMR studies on Pt and Pd metal nanoparticle systems that report similar phenomena where the bulk component is clearly identified as a separate component to the disordered surface and sub-surface speciation of lower translational symmetry. ${ }^{55-57}$ 

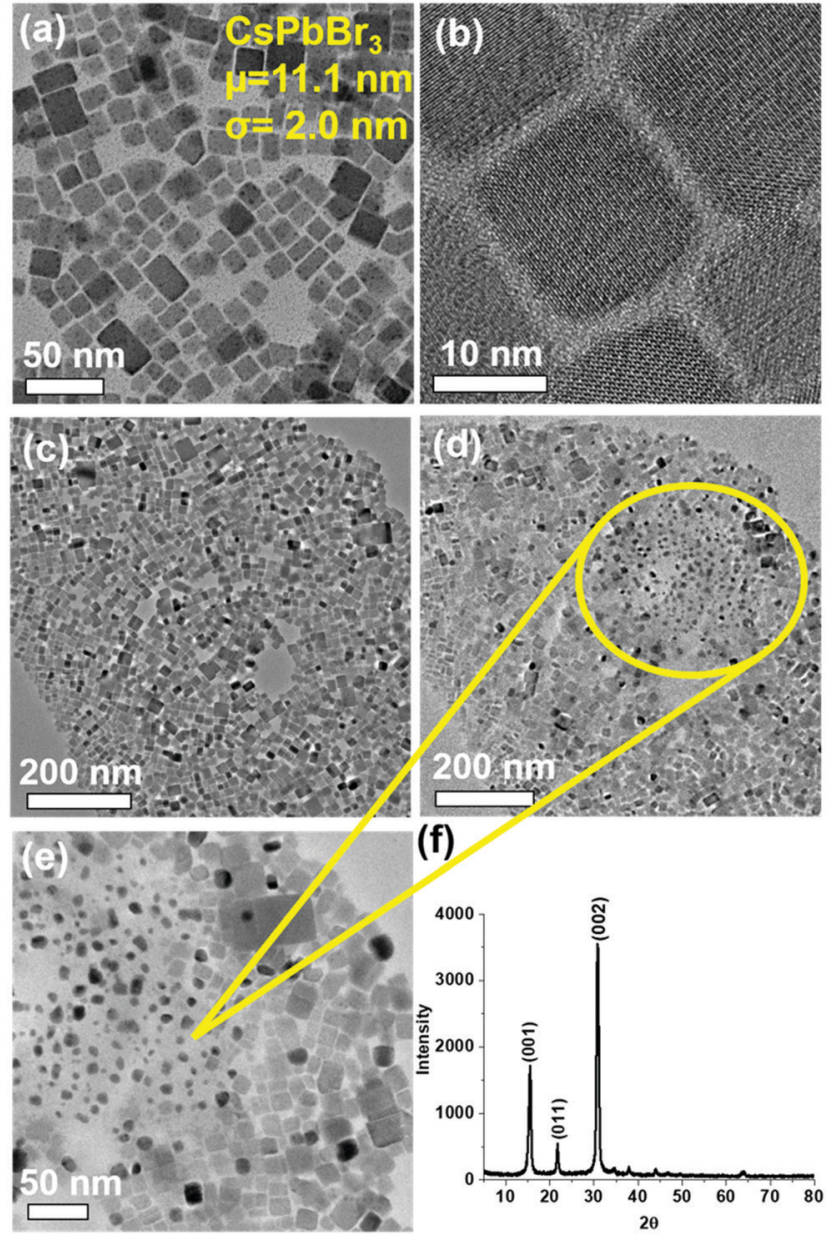

$2 \theta$

Fig. 2 HR-TEM micrographs of $\mathrm{CsPbBr}_{3}$ nanoparticles synthesized using LARP method showing (a) the as-synthesized cubic morphology, (b) a higher resolution image emphasizing the cube structure and the lattice fringes, (c) a lower resolution region scan acquired with short beam exposure of $\sim 5 \mathrm{~s}$, (d) lower resolution scan of the same area after a beam exposure of $\sim 15 \mathrm{~s}$, (e) a resolution micrograph depicting the disorder caused by beam damage after the same $\sim 15 \mathrm{~s}$ beam exposure, and (f) the XRD pattern of as synthesized $\mathrm{CsPbBr}_{3}$ nanoparticles.

Within the nominal stoichiometry of the triple cation $\mathrm{Cs}_{x}\left(\mathrm{MA}_{0.17} \mathrm{FA}_{0.83}\right)_{1-x} \mathrm{PbBr}_{3}(x=0-0.15)$ nanocrystal series the $\mathrm{Cs}^{+}$cation is a dilute species, and a more complex scenario describes the Cs speciation in these systems. In comparison to the $\mathrm{CsPbBr}_{3}$ cases, the ${ }^{133} \mathrm{Cs}$ MAS NMR data in Fig. 3a now exhibits upfield shifted resonances at $\delta \leq 65 \mathrm{ppm}$, however the observed chemical shift and multiplicity of the observed resonances is sensitive to the degree of Cs incorporation. For the highest Cs concentration sample (15 mol\%) only a single discrete ${ }^{133} \mathrm{Cs}$ resonance at $\delta \sim 65 \mathrm{ppm}$ is observed suggesting that the $\mathrm{Cs}^{+}$cations in the larger $\sim 8 \mathrm{~nm}$ diameter spheroids generate a Cs-rich core within the nanoparticles, thus generating a 'pseudo core-shell' arrangement which is insensitive to the surface and sub-surface layers. In contrast, the smaller $10 \mathrm{~mol} \%$ and $5 \mathrm{~mol} \%$ systems supporting reduced Cs incorporation exhibit successive upfield shifts (to lower ppm) in the primary bulk ${ }^{133} \mathrm{Cs}$ resonances to $\delta \sim 61$ and $\delta \sim 58 \mathrm{ppm}$, (a)
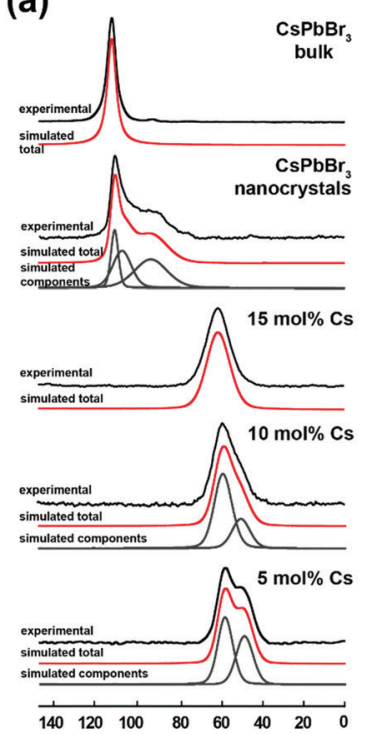

$\delta{ }^{133} \mathrm{Cs}$ Chemical Shift (ppm) (b)

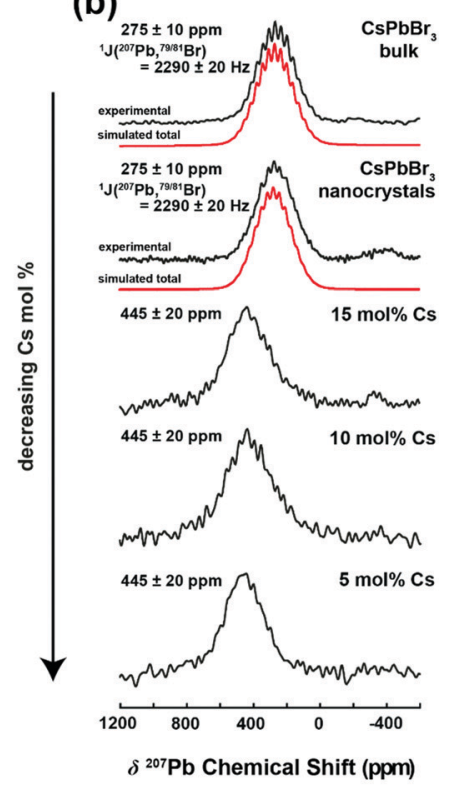

(c)

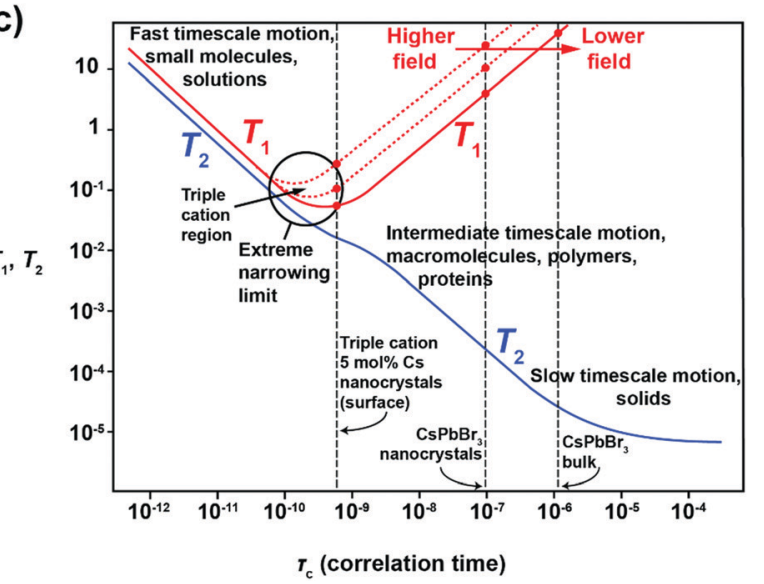

Fig. 3 The (a) ${ }^{133} \mathrm{Cs}$ MAS NMR data $\left(B_{0}=14.1 \mathrm{~T}, \nu_{\mathrm{r}}=12 \mathrm{kHz}\right)$, and $(\mathrm{b}){ }^{207} \mathrm{~Pb}$ MAS NMR data $\left(B_{0}=7.05 \mathrm{~T}, \nu_{\mathrm{r}}=20 \mathrm{kHz}\right)$, characterizing triple cation $\mathrm{Cs}_{x}\left(\mathrm{MA}_{0.17} \mathrm{FA}_{0.83}\right)_{1-x} \mathrm{PbBr}_{3}(x=0.05-0.15)$ and $\mathrm{CsPbBr}_{3}$ nanocrystal systems, while (c) depicts the relative motional regimes assumed by these systems as described by their $T_{1}$ characteristics under the influence of a dipolar relaxation mechanism.

respectively, and additional upfield resonances at $\delta \sim 51 \mathrm{ppm}$ (10 mol\% Cs sample) and $\delta \sim 49 \mathrm{ppm}$ ( $5 \mathrm{~mol} \%$ Cs sample) are also observed. These findings suggest that the Cs-rich core of these smaller spheroidal triple cation nanocrystals experiences an increased interaction with the particle surface, and that these systems diverge from a formal pseudo core-shell arrangement. Hence, the relative proportions and influence of the surface/sub-surface layers to the bulk (core) are becoming more apparent as the surface area:volume ratio of these smaller nanocrystals increases. These observations are analogous to the characteristics defining the Cs speciation within the $\sim 11 \mathrm{~nm}$ $\mathrm{CsPbBr}_{3}$ nanocrystal system discussed above (see Fig. 3a), where significant proportions of the Cs positions experience increased structural disorder and altered chemical environments due to proximity to the nanoparticle surface. 


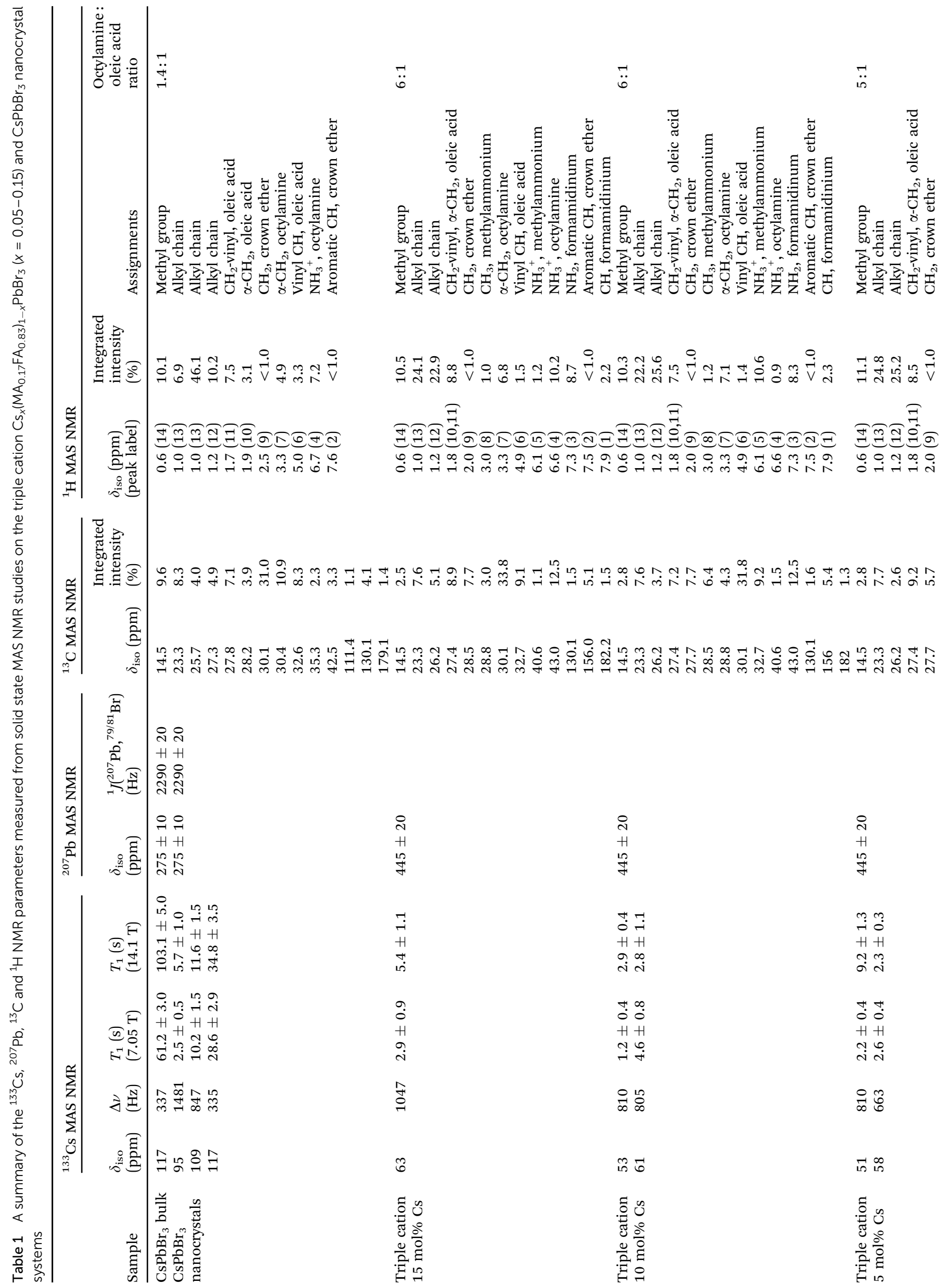


The ${ }^{133}$ Cs $T_{1}$ data summarised in Table 1 , and depicted in Fig. 3c and Fig. S4a-e (ESI $\ddagger$ ), yield valuable insights into the motional dynamics of the Cs speciation within the $\mathrm{CsPbBr}$ bulk and nanocrystal phases, and the triple cation $\mathrm{Cs}_{x}\left(\mathrm{FA}_{0.83-}\right.$ $\left.\mathrm{MA}_{0.17}\right)_{1-x} \mathrm{PbBr}_{3}(x=0-0.15)$ nanocrystal series. Assuming that the relaxation of these spin systems is dominated by a dipolar relaxation mechanism, ${ }^{58}$ the long $T_{1}$ values measured from $\mathrm{CsPbBr}_{3}$ bulk phase $\left(\delta 117 \mathrm{ppm} ; T_{1} \sim 61 \mathrm{~s}\right.$ at $7.05 \mathrm{~T}$; $T_{1} \sim 103 \mathrm{~s}$ at $\left.14.1 \mathrm{~T}\right)$ demonstrate that $\mathrm{Cs}^{+}$dynamics reside in the slow motion regime that is characteristic of condensed solids behaviour (see Fig. 3c). In contrast, while the bulk component of the $\mathrm{CsPbBr}_{3}$ nanocrystal phases exhibits similar $\mathrm{Cs}^{+}$dynamics behaviour although the measured $T_{1}$ values are not as long ( $\delta 117 \mathrm{ppm} ; T_{1} \sim 29 \mathrm{~s}$ at $7.05 \mathrm{~T} ; T_{1} \sim 35 \mathrm{~s}$ at $14.1 \mathrm{~T}$ ), the resonances ascribed to sub-surface $(\delta 109 \mathrm{ppm})$ and surface ( $\delta 95 \mathrm{ppm}) \mathrm{Cs}^{+}$cations positions are characterised by significantly shorter $T_{1} \mathrm{~s}$ of $\sim 3-12 \mathrm{~s}$ which decrease monotonically as the particle surface is approached, and they display reducing magnitude differences between the variable $B_{0}$ field values. These features indicate that the $\mathrm{Cs}^{+}$cation migration within these regions is much faster and they reside in a motional regime approaching the extreme narrowing limit, as schematically represented in Fig. 3c. These results corroborate previous computational and electric field driven ion migration studies in mixed metal halide perovskite nanocrystal systems which report increased $\mathrm{Cs}^{+}$and $\mathrm{Br}^{-}$dynamics in surface species in the presence of increased defect and vacancy structures on the nanocrystal surfaces. ${ }^{32,59}$

In comparison to the partitioned ${ }^{133} \mathrm{Cs} T_{1}$ behaviour based on the proximity of the Cs species to the $\mathrm{CsPbBr}_{3}$ nanocrystal surface, the $T_{1}$ relaxation of the $\mathrm{Cs}^{+}$cations within the triple cation systems is more complicated as each $\mathrm{Cs}^{+}$position is now surrounded by $\mathrm{MA}^{+}$and $\mathrm{FA}^{+}$positions undergoing their own dynamic processes. Hence, the ${ }^{133}$ Cs $T_{1}$ behaviour can no longer be rationalised to slower or faster $\mathrm{Cs}^{+}$migration governed by a simplistic 'proximity-to-surface' phenomenon. As noted from Table 1, Fig. 3c and Fig. S4a-e (ESI $\ddagger$ ), the contrast between the magnitudes of the $T_{1}$ values has largely disappeared. These data show that the triple cation nanocrystals are characterised by consistently shorter $T_{1}$ values in comparison to the $\mathrm{CsPbBr}_{3}$ nanocrystals. They also exhibit little variation (within experimental error) between the variable $B_{0}$ field values; i.e. they nearly all reside in motional regimes close to the extreme narrowing limit as depicted in Fig. $3 c .{ }^{58}$ The only exception to this behaviour is the $\delta 51 \mathrm{ppm}$ resonance assigned to surface/ near-surface $\mathrm{Cs}^{+}$species in the $5 \mathrm{~mol} \%$ Cs system which shows clear variable $B_{0}$ field separation in the measured $T_{1}$ values $(\delta 51 \mathrm{ppm} ; \sim 2 \mathrm{~s}$ at $7.05 \mathrm{~T} ; \sim 9 \mathrm{~s}$ at $14.1 \mathrm{~T})$, thus suggesting residence in a slower motion regime associated with decreased $\mathrm{Cs}^{+}$migration dynamics. It can be assumed that the $\mathrm{MA}^{+}$and $\mathrm{FA}^{+}$dynamics modulating the local magnetic fields at the surface, subsurface and bulk $\mathrm{Cs}^{+}$positions are approximately constant for all the triple cation nanocrystals; hence, the longer, field dependent $T_{1}$ s for the $5 \mathrm{~mol} \%$ system indicate reduced $\mathrm{Cs}^{+}$migration linked with the higher $\mathrm{Cs}^{+}$ surface concentration and increased passivation (see Fig. 3a) 
leading to greater surface environmental stability from that preparation. $^{23}$

Increased disorder induced by reduced particle size effects is further demonstrated by the ${ }^{207} \mathrm{~Pb}$ MAS NMR data of Fig. $3 \mathrm{~b}$. The data for bulk $\mathrm{CsPbBr}_{3}(\delta 275 \mathrm{ppm})$ exhibits a well-defined ${ }^{1} J\left({ }^{207} \mathrm{~Pb},{ }^{79 / 81} \mathrm{Br}\right)$ coupling of $2290 \pm 20 \mathrm{~Hz}$ from the cubic $\mathrm{PbBr}_{6}{ }^{4-}$ framework. Moreover, the corresponding data for the $\mathrm{CsPbBr}_{3}$ nanocrystal is characterised a less resolved/broadened ${ }^{1} J\left({ }^{207} \mathrm{~Pb},{ }^{79 / 81} \mathrm{Br}\right)$ coupling manifold due to the disorder induced by increased structural strain and dislocations as the nanoparticle surface plays a more prominent role. These results represent the first observations of ${ }^{1} J\left({ }^{207} \mathrm{~Pb},{ }^{79 / 81} \mathrm{Br}\right)$ coupling in $\mathrm{CsPbr}_{3}$ from both bulk and nanocrystalline forms. In contrast, the ${ }^{207} \mathrm{~Pb}$ MAS NMR data from the triple cation series represent broad featureless resonances ( $\delta 445 \mathrm{ppm}$ ) devoid of any ${ }^{1} J\left({ }^{207} \mathrm{~Pb},{ }^{79 / 81} \mathrm{Br}\right)$ fine structure, thus reflecting the cation disorder that characterises these systems.

The ${ }^{13} \mathrm{C}$ and ${ }^{1} \mathrm{H}$ MAS NMR data from the triple cation $\mathrm{Cs}_{x}\left(\mathrm{MA}_{0.17} \mathrm{FA}_{0.83}\right)_{1-x} \mathrm{PbBr}_{3}(x=0-0.15)$ nanocrystal preparations are shown in Fig. 4 and 5. These data describe the $\mathrm{H}$ and $\mathrm{C}$ speciation emanating from the $\mathrm{MA}^{+}$and $\mathrm{FA}^{+}$cations within the nanoparticle, and the more complex speciation associated with the octylamine and oleic acid passivating agents on the nanoparticle surface. An integration of the $\mathrm{MA}^{+}$and $\mathrm{FA}^{+}$resonances in both the ${ }^{13} \mathrm{C}$ and ${ }^{1} \mathrm{H}$ MAS NMR data (see Fig. $4 \mathrm{a}-\mathrm{c}$ ) shows that the relative proportions of these cations are close to that of the proposed nominal stoichiometry, and within experimental error this ratio is invariant across the $0-15 \mathrm{~mol} \%$ Cs compositional range. As summarised in Fig. 4c, these characteristics corroborates the quantitative analysis undertaken using the TEM-EDXS technique. Most importantly, this finding suggests that the trends characterizing the ${ }^{133}$ Cs MAS NMR data are formally ascribed to the changing nanocrystal size and the proximity of the Cs speciation to the particle surface, and not to other factors linked to variation in the $\mathrm{FA}^{+}$and $\mathrm{MA}^{+}$cation concentrations.

\section{Multinuclear solid state NMR - nanocrystal surface}

Complete assignments of the ${ }^{1} \mathrm{H}$ MAS NMR spectra characterizing the triple cation $\mathrm{Cs}_{x}\left(\mathrm{MA}_{0.17} \mathrm{FA}_{0.83}\right)_{1-x} \mathrm{PbBr}_{3}(x=0.15)$ and $\mathrm{CsPbBr}_{3}$ nanocrystal systems are shown in Fig. 5a and b, respectively. These assignments were assisted by connectivity information drawn from two different solid state 2D homonuclear ${ }^{1} \mathrm{H}-{ }^{1} \mathrm{H}$ MAS NMR methodologies. As observed from Fig. 6 and 7, the double quantum/single quantum (DQ/SQ) BAck-to-BAck (BABA) and Nuclear Overhauser Effect SpectroscopY (NOESY) experiments were implemented which provided through-bond and through-space ('direct') information, respectively. For the triple cation system $\left(\mathrm{Cs}_{0.15}\left(\mathrm{MA}_{0.17} \mathrm{FA}_{0.83}\right)_{0.85}\right.$ $\left.\mathrm{PbBr}_{3}\right)(x=15 \mathrm{~mol} \% \mathrm{Cs}$ in this case), Fig. 6a shows the 2D DQ/SQ BABA data that clearly defines through-bond connectivity within the $\mathrm{FA}^{+}$cation, and within the octylamine passivating agent on the nanocrystal surface. These correlations proved to be valuable assignment aids. In contrast, the $2 \mathrm{D}$ ${ }^{1} \mathrm{H}-{ }^{1} \mathrm{H}$ NOESY data from the same system (see Fig. $6 \mathrm{~b}$ and c) provides a more complex array of through-space connectivities (a)

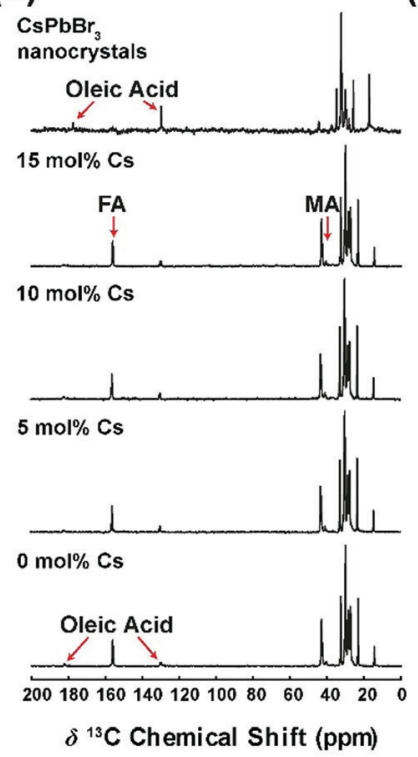

(c)

(d)
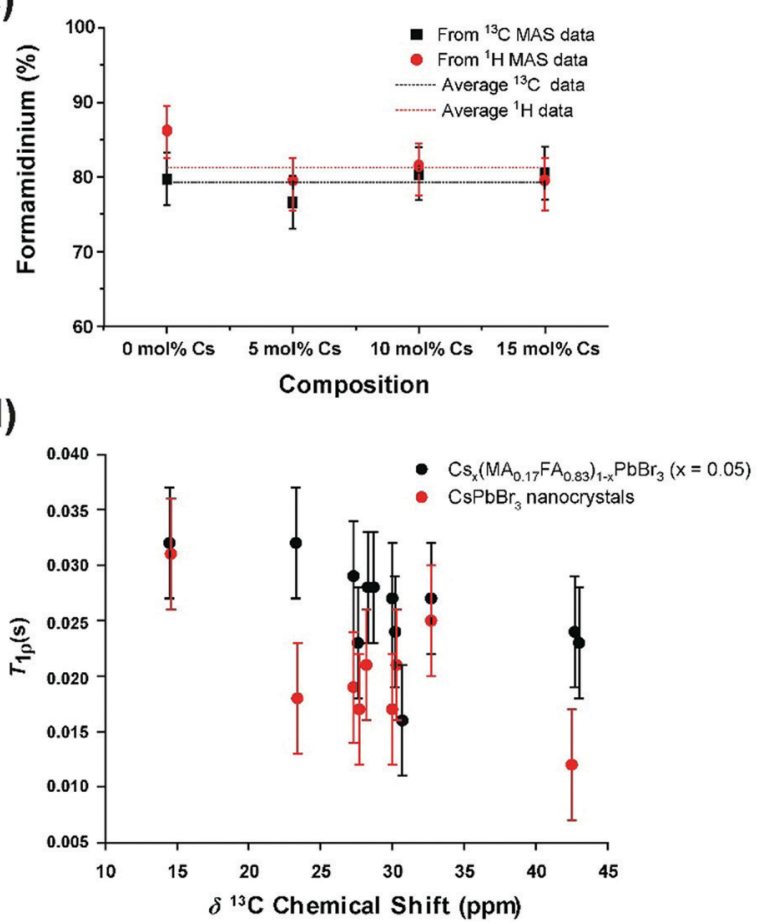

Fig. 4 The (a) ${ }^{13} \mathrm{C}$ MAS NMR data $\left(B_{0}=14.1 \mathrm{~T}, \nu_{\mathrm{r}}=12 \mathrm{kHz}\right)$, (b) ${ }^{1} \mathrm{H}$ MAS NMR data $\left(B_{0}=14.1 \mathrm{~T}, \nu_{\mathrm{r}}=60 \mathrm{kHz}\right)$, (c) quantitative estimates of the $\mathrm{MA}^{+}$ and $\mathrm{FA}^{+} \mathrm{A}$ site cation concentrations as determined from the ${ }^{13} \mathrm{C}$ and ${ }^{1} \mathrm{H}$ MAS NMR data, and (d) comparison of the ${ }^{1} \mathrm{H} T_{1 \mathrm{p}}$ data from the triple cation $\mathrm{Cs}_{x}\left(\mathrm{MA}_{0.17} \mathrm{FA}_{0.83}\right)_{1-x} \mathrm{PbBr}_{3}(x=0.05)$ and $\mathrm{CsPbBr}_{3}$ nanocrystal systems. The ${ }^{13} \mathrm{C}$ and ${ }^{1} \mathrm{H}$ MAS NMR data both suggest invariant proportions of $\mathrm{MA}$ and $\mathrm{FA}$ across the compositional range as summarized in (c), which is consistent with the nominal stoichiometric proportions introduced in the synthesis route.

amongst the $\mathrm{FA}^{+}, \mathrm{MA}^{+}$, octylamine and oleic acid species that are both intermolecular and intramolecular in nature. These assignments enabled an unambiguous identification of the octylamine and oleic acid passivating agents populating the 

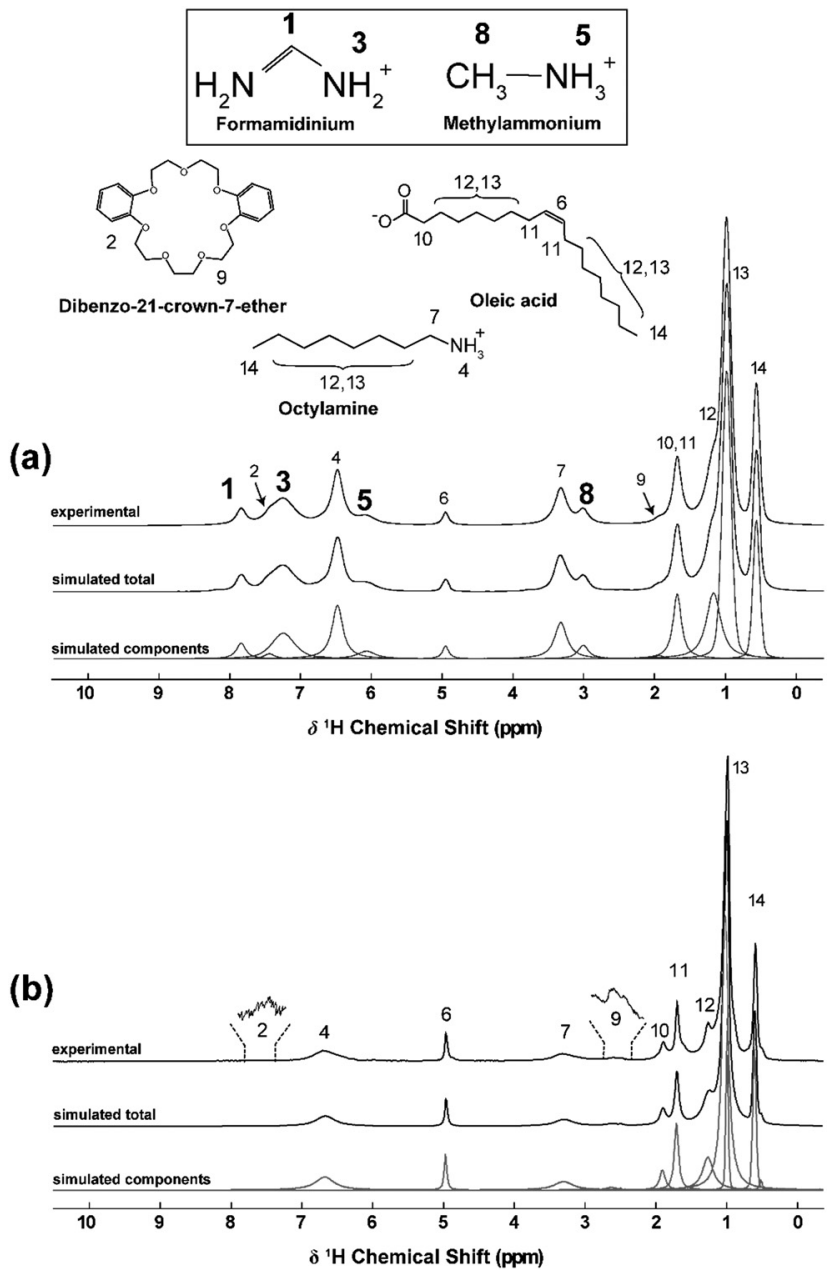

Fig. $5 \mathrm{~A}{ }^{1} \mathrm{H}$ MAS NMR data $\left(B_{0}=14.1 \mathrm{~T}, \nu_{\mathrm{r}}=60 \mathrm{kHz}\right)$ from, (a) the triple cation $\mathrm{Cs}_{x}\left(\mathrm{MA}_{0.17} \mathrm{FA}_{0.83}\right)_{1-x} \mathrm{PbBr}_{3}(x=0.15)$ nanocrystal system, and (b) the $\mathrm{CsPbBr}_{3}$ nanocrystal system, highlighting resonances from the $\mathrm{FA}^{+}$and $\mathrm{MA}^{+} \mathrm{A}$-site cations, the octylamine and oleic acid surface passivating agents, and the trace amounts of the dibenzo-21-crown-7-ether solvent. The data from solid state 2D homonuclear ${ }^{1} \mathrm{H}-{ }^{1} \mathrm{H}$ BABA and NOESY experiments assisted these assignments.

nanocrystal surfaces, and they facilitated quantitative estimates to be established.

Although the triple cation precursor solution is comprised of $5 \%$ octylamine and $95 \%$ oleic acid, the quantitative estimates from deconvolution and simulation of the solid state ${ }^{1} \mathrm{H}$ MAS NMR data of Fig. 5a establish that the bulk of the nanocrystal surface passivation is actually dominated by the lower concentration octylamine component. The quantitative estimate for the $15 \mathrm{~mol} \%$ Cs sample shows that the surface is populated by $\sim 86 \% \pm 4$ octylamine $v s . \sim 14 \% \pm 3$ oleic acid (i.e. a ratio of $\sim 6: 1)$. From the similarity exhibited in the triple cation 1D ${ }^{1} \mathrm{H}$ MAS NMR data of Fig. $4 \mathrm{~b}$ and the corresponding triple cation $2 \mathrm{D}{ }^{1} \mathrm{H}^{-1} \mathrm{H}$ BABA and ${ }^{1} \mathrm{H}-{ }^{1} \mathrm{H}$ NOESY data displayed in Fig. $6 \mathrm{a}-\mathrm{c}$ and Fig. S6 (ESI $\$$ ), the entire triple cation series is characterized by this feature. As summarized in Table 1 , the octylamine:oleic acid ratio ranges from $\sim 1: 5-1: 6$. These observations demonstrates that the sterically smaller octylamine molecule with a positively charged amine group dominates the nanocrystal surface, thus supporting the presence of a residual negative surface charge from the $\mathrm{PbBr}_{6}{ }^{4-}$ framework. ${ }^{60}$ Such a scenario can only occur if there exists a predominance of exposed $\mathrm{Br}^{-}$positions undergoing ionic contact with the octylamine $\mathrm{NH}_{3}{ }^{+}$head group, as depicted in the schematic representations in Fig. 7a and b. The description of the triple cation nanocrystal surface contrasts markedly with that of the $\mathrm{CsPbBr}_{3}$ nanocrystal surface illustrated in Fig. 8c. From the quantitative ${ }^{1} \mathrm{H}$ and ${ }^{13} \mathrm{C}$ MAS NMR analyses describing the $\mathrm{CsPbBr}_{3}$ system it is evident that a greater proportion of oleic acid is present on this surface, however octylamine still represents the larger component $(\sim 60 \% \pm 4$ octylamine $v s$. $\sim 40 \% \pm 4$ oleic acid; i.e. $\sim 3: 2$ ). This implies that more equivalent distributions of $\mathrm{Br}^{-}$and $\mathrm{Cs}^{+}$species populate this surface (see Fig. 7c). Another important outcome described by the ${ }^{1} \mathrm{H}$ and ${ }^{13} \mathrm{C}$ MAS NMR data from both the $\mathrm{CsPbBr}_{3}$ and triple cation nanocrystal systems is that the dibenzo-21-crown7 -ether is present in trace amounts only ( $\sim 1 \%$ level $)$, consequently eliminating any likelihood that it exhibits a functional role on these surfaces.

The different octylamine: oleic acid ratios supported by the triple cation and $\mathrm{CsPbBr}_{3}$ nanocrystal surfaces directly influence the mobility of these surface passivation agents. Fig. $4 \mathrm{~d}$ summarizes the ${ }^{1} \mathrm{H} T_{1 \rho}$ relaxation time measurements associated with each $\mathrm{H}$ species populating these surfaces. This relaxation time is sensitive to different modes of molecular motion and reorientation in the millisecond regime. ${ }^{58}$ These data indicate that (apart from the chain-end $\mathrm{CH}_{3}$ species in both passivating agents that are controlled by methyl rotation), the $\mathrm{H}$ species on triple cation surfaces (dominated by octylamine) display consistently longer $T_{1 \rho}$ relaxation times emanating from slower segmental motion in the octylamine chain. Conversely, the $\mathrm{CsPbBr}_{3}$ surface which possesses a higher oleic acid population exhibits shorter $T_{1 \rho}$ relaxation times associated with the faster segmental motion of the much longer aliphatic chain of this molecule. These observations directly correlate with the higher stability of the triple cation nanocrystals in comparison to their $\mathrm{CsPBBr}_{3}$ counterparts (see the HR-TEM results above), with the former possessing a more homogeneous surface environment characterized by slower modes of motion with lower energetics.

The $2 \mathrm{D}{ }^{1} \mathrm{H}-{ }^{1} \mathrm{H}$ NOESY experiment is a technique that relies on the transferral of spin polarisation from a specific ${ }^{1} \mathrm{H}$ nucleus to other surrounding ${ }^{1} \mathrm{H}$ nuclei in the structure via the homonuclear ${ }^{1} \mathrm{H}-{ }^{1} \mathrm{H}$ dipolar interaction. In cases where $\mathrm{H}$ species are sufficiently proximate, an enhancement in the observed NMR signal from the neighboring nuclei can be observed which is proportional to the strength of the ${ }^{1} \mathrm{H}^{-1} \mathrm{H}$ dipolar coupling. This phenomenon is limited by the $1 / r^{6}$ dependence of this interaction, and the dipolar contact between spatially distant $\mathrm{H}$ species can only be detected when they are separated by distances of typically less than $\sim 6 \AA^{60-62}$ These characteristics render the sensitivity of this experiment to be limited to $\mathrm{H}-\mathrm{H}$ distances within one framework cavity (i.e. ranging between 2.0-3.0 $)$ ), and intermolecular $\mathrm{H}-\mathrm{H}$ distances between neighboring framework cavities (i.e. ranging between $\sim 3.5-6.0 \AA$ ). 
(a)

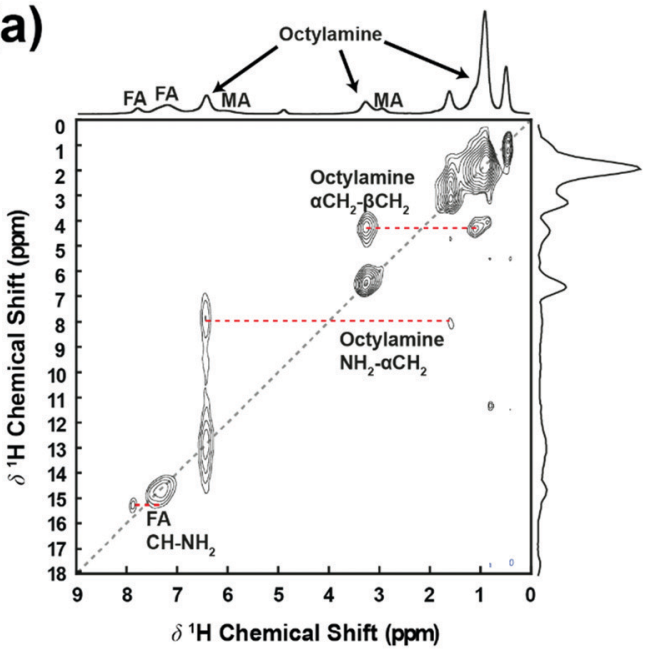

(b)

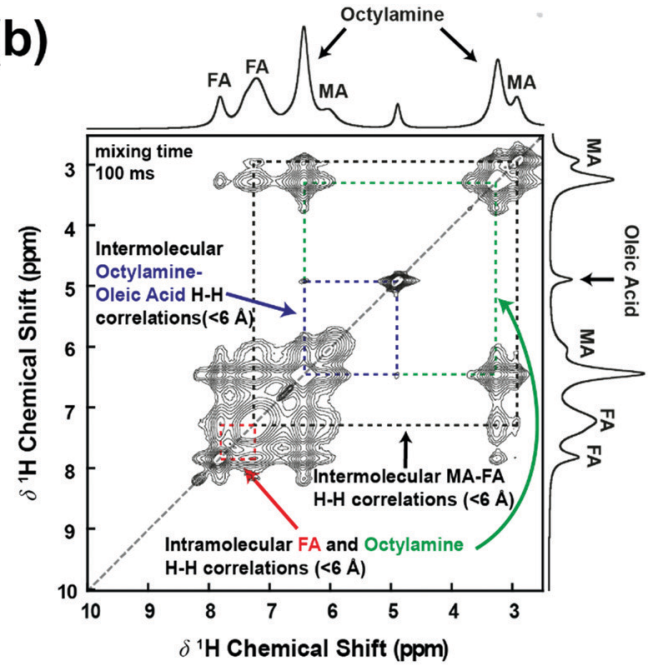

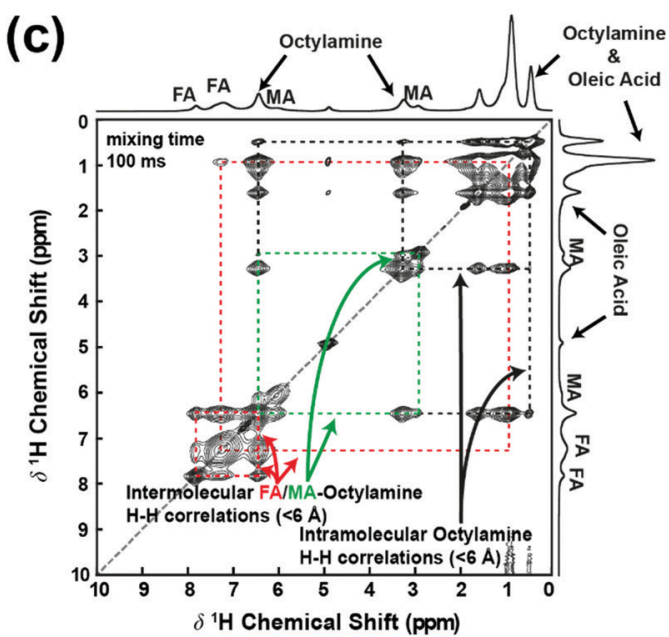

Fig. $62 \mathrm{D}$ homonuclear ${ }^{1} \mathrm{H}-{ }^{1} \mathrm{H}$ MAS NMR data $\left(B_{0}=14.1 \mathrm{~T}, \nu_{\mathrm{r}}=60 \mathrm{kHz}\right)$ from the triple cation $\mathrm{Cs}_{x}\left(\mathrm{MA}_{0.17} \mathrm{FA}_{0.83}\right)_{1-x} \mathrm{PbBr}_{3}(x=0.15)$ system including $(a) 2 \mathrm{D}$ $\mathrm{DQ} / \mathrm{SQ} \mathrm{BABA}$ data showing through-bond connectivities (indicated with red dashed line) within the FA $\mathrm{A}^{+}$cation and within the octylamine, passivating agent, and (b) 2D NOESY data (mixing time $100 \mathrm{~ms}$ ) highlighting through-space connectivities associated with intramolecular FA (red) and octylamine (green) correlations, and intermolecular $\mathrm{MA}^{+} / \mathrm{FA}^{+}$correlations (black), octylamine/oleic acid correlations (blue). (c) Shows an expanded representation of (b) highlighting additional octylamine/MA+ (green) and octylamine/FA ${ }^{+}$(red) correlations, and intramolecular octylamine correlations (black).

However, $\mathrm{MA}^{+}$and $\mathrm{FA}^{+}$cations in next-nearest-neighbour arrangements exhibit $\mathrm{H}-\mathrm{H}$ distances of $>10 \AA$ which are outside the detection limits of this technique. An intermediate mixing time $(\tau)$ of $100 \mathrm{~ms}$ allows short range and long range correlations to be detected in the 2D MAS NMR data of Fig. $6 \mathrm{~b}$ and $\mathrm{c}$. A typical analysis of this demarcation of cation $\mathrm{H}-\mathrm{H}$ distances in a lead halide perovskite is given for the $\mathrm{MAPbBr}_{3}$ system in Fig. S5 (ESI $\ddagger$ ).

The sensitivity limits intrinsic to the $2 \mathrm{D}{ }^{1} \mathrm{H}-{ }^{1} \mathrm{H}$ NOESY experiment have implications for the interpretation of the correlations pertaining to the octylamine and oleic acid passivating agent on the nanocrystal surfaces. From Fig. $6 \mathrm{c}$ prominent intermolecular $\mathrm{FA}^{+}$/octylamine correlations are observed, while weaker $\mathrm{MA}^{+}$/octylamine correlations are also evident. The intensity of these correlations demonstrates that the octylamine (with a positively charged $\mathrm{NH}_{3}{ }^{+}$functional group) exhibits a strong affinity for the $\mathrm{PbBr}_{6}{ }^{4-}$ surface which supports a large negative charge; i.e. the $\mathrm{Br}^{-}$positions provide the primary point of electrostatic contact. However, the positively charged surface $\mathrm{MA}^{+}$ and $\mathrm{FA}^{+}$cations (which will be notionally coordinated to the lower concentration oleic acid $\mathrm{CO}_{2}{ }^{-}$functional group) are adjacent to the primary $\mathrm{Br}^{-}$positions and spatially separated by $<\sim 6 \AA$ as per the sensitivity limits of the NOESY experiment. The intensity differences in these correlations are due to the proportionally smaller concentrations of $\mathrm{MA}^{+}$in the nominal stoichiometry rather than from spatial separation considerations (see Fig. 4c). It is important to recognize that only the surface $\mathrm{FA}^{+}$/octylamine and $\mathrm{MA}^{+}$/octylamine correlations are observed in Fig. $6 \mathrm{~b}$ and $\mathrm{c}$ as the sub-surface $\mathrm{FA}^{+}$and $\mathrm{MA}^{+}$cations are $>10 \AA$ away (see Fig. 8a). This representation provides an initial depiction of the highly disordered nature of the triple cation nanocrystal surface.

The surface $\mathrm{FA}^{+}$/octylamine and $\mathrm{MA}^{+}$/octylamine correlations of Fig. $6 \mathrm{c}$ also provide additional evidence for preferential alignment so that the electrostatic repulsion between the positively charged amine groups and the positively charged octylamine head group is minimized. This phenomenon is evidenced by 


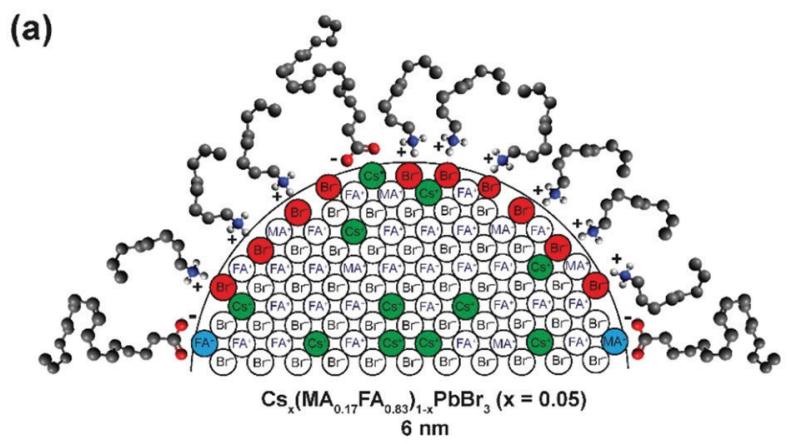

(d)

(b)

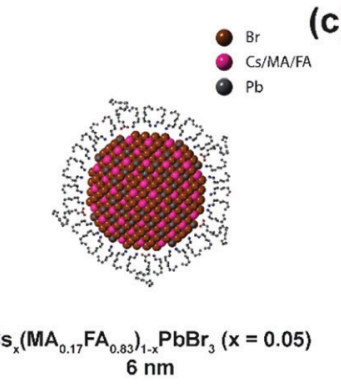

$6 \mathrm{n}$
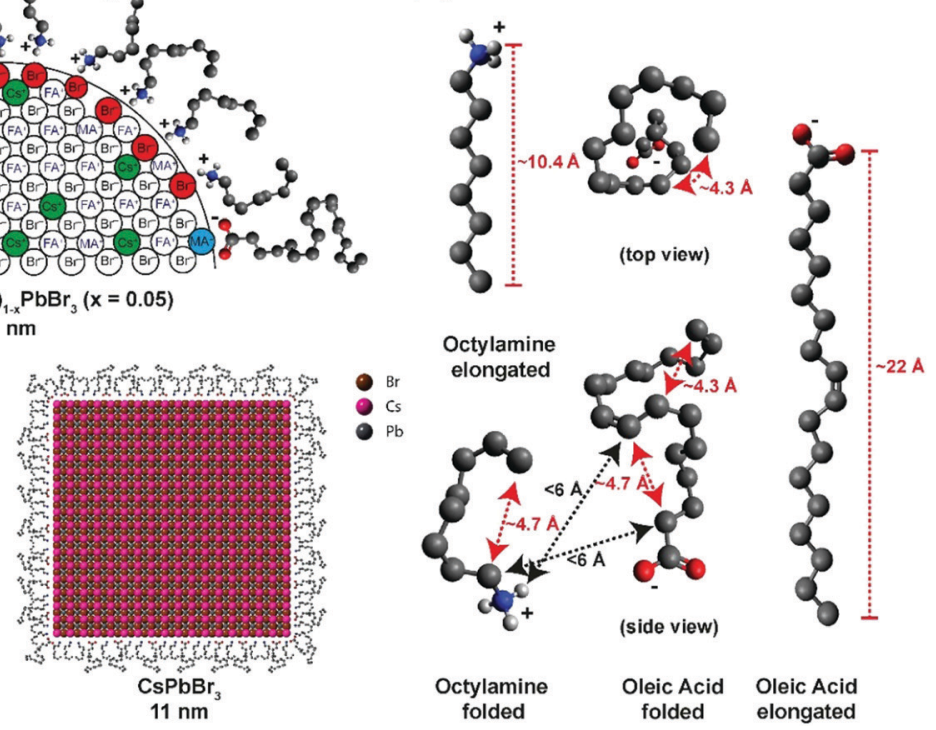

Fig. 7 Schematic representation of the surface passivation of the triple cation $\mathrm{Cs}_{x}\left(\mathrm{MA}_{0.17} \mathrm{FA}_{0.83}\right)_{1-x} \mathrm{PbBr}_{3}(x=0.05-0.15)$ and $\mathrm{Cs} \mathrm{PbBr} 3 \mathrm{nanocrystal}$ systems showing, (a) a typical arrangement of the disordered coordination of the octylamine and oleic acid passivating agents on the surface of the 5 mol\% Cs ( $\sim 6 \mathrm{~nm}$ ) sample (not to scale, $\mathrm{PbBr}_{6}{ }^{4-}$ framework excluded), (b) and (c) representations of the 5 mol\% Cs ( $\sim 6 \mathrm{~nm}$ ) and CsPbBr 3 nanoparticle surfaces supporting different proportions of the octylamine and oleic acid passivating agents, and (d) folded configurations of the octylamine and oleic acid as determined from the solid state $2 \mathrm{D}{ }^{1} \mathrm{H}-{ }^{1} \mathrm{H}$ NOESY data presented in Fig. 6 and 7.
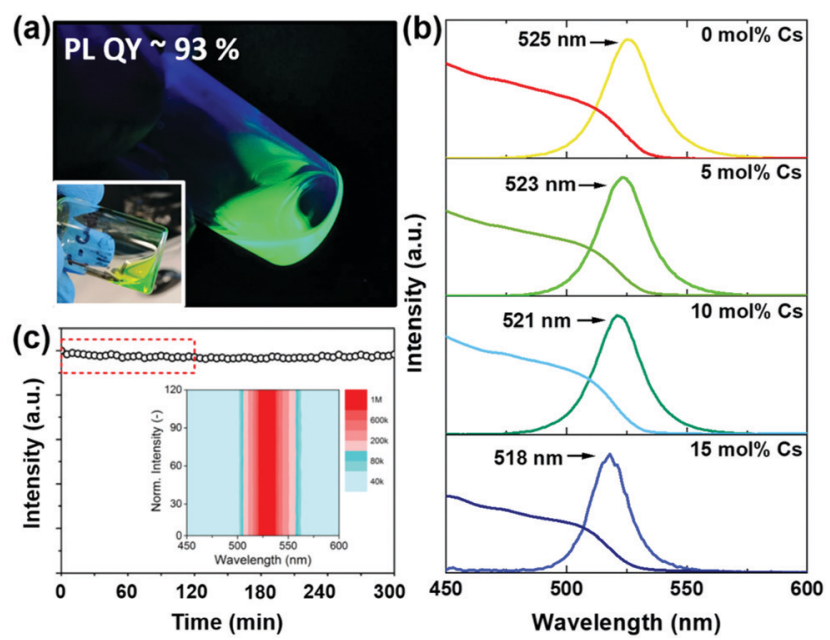

Fig. 8 The photophysical properties from the triple cation $\mathrm{Cs}_{x}\left(\mathrm{MA}_{0.17} \mathrm{FA}_{0.83}\right)_{1-x} \mathrm{PbBr}_{3}(x=0-0.15)$ series depicting, (a) a photograph of the $5 \mathrm{~mol} \% \mathrm{Cs}$ sample in hexane under room light and $365 \mathrm{~nm}$ wavelength UV light, (b) absorption and PL spectra of 0 mol\% Cs, 5 mol\% Cs, 10 mol\% Cs, 15 mol\% Cs samples, and (c) the photostability of a triple cation nanocrystal thin film measured under continuous illumination for $5 \mathrm{~h}$ (maximum intensity recorded for PL maximum at $528 \mathrm{~nm}$ $\left.\left(\lambda_{\text {exc }}=350 \mathrm{~nm}\right)\right)$. The inset in (c) shows 2D PL spectra recorded over the first $2 \mathrm{~h}$ of continuous illumination emphasizes the absence of intensity changes or spectral drift in this performance.

the observable $\mathrm{CH}\left(\mathrm{FA}^{+} ; \delta 7.9 \mathrm{ppm}\right) / \mathrm{NH}_{3}{ }^{+}$(octylamine; $\left.\delta 6.5 \mathrm{ppm}\right)$ and $\mathrm{NH}_{2}{ }^{+}\left(\mathrm{FA}^{+} ; \delta 7.3 \mathrm{ppm}\right) / \mathrm{CH}_{3}$ (octylamine; $\delta 1.0 \mathrm{ppm}$ ) correlations marked in red, and the weaker $\mathrm{CH}_{3}\left(\mathrm{MA}^{+} ; \delta 3.0 \mathrm{ppm}\right) / \mathrm{NH}_{3}{ }^{+}$ (octylamine; $\delta 6.5 \mathrm{ppm}$ ) correlation marked in green (see Fig. 6c).
Note that the $\mathrm{NH}_{2}^{+}\left(\mathrm{FA}^{+} ; \delta 7.2 \mathrm{ppm}\right) / \mathrm{NH}_{3}^{+}$(octylamine; $\left.\delta 6.5 \mathrm{ppm}\right)$ and the $\mathrm{NH}_{3}^{+}\left(\mathrm{MA}^{+} ; \delta 6.1 \mathrm{ppm}\right) / \mathrm{NH}_{3}{ }^{+}$(octylamine; $\delta 6.5 \mathrm{ppm}$ ) correlations are absent. As demonstrated in Fig. S6 (ESI $\ddagger$ ), these surface structural characteristics are common to all the samples in the $5-15 \mathrm{~mol} \%$ Cs compositional range of the triple cation nanocrystal system.

In addition, the intramolecular and intermolecular correlations emanating from the $2 \mathrm{D}^{1} \mathrm{H}^{-1} \mathrm{H}$ NOESY data in Fig. $6 \mathrm{~b}, \mathrm{c}$ and Fig. S7b-e (ESI ) permit insights into the structural arrangement of the octylamine and oleic acid passivating agents on the triple cation and $\mathrm{CsPbBr}_{3}$ nanocrystal surfaces to be derived. Simple pictorial representations depicting these long-chain aliphatic species as notionally radiating outwards from these nanocrystal surfaces (see Fig. $7 d$ ) do not account for the complex array of correlations observed in Fig. 6b, c and Fig. S7b-e (ESI $\ddagger$ for the triple cation and $\mathrm{CsPbBr}_{3}$ nanocrystal surfaces, respectively. The fully elongated octylamine and oleic acid configurations represented in Fig. $7 \mathrm{~d}$ are $\sim 10$ and $\sim 22 \AA$ in length, respectively, suggesting that the $\mathrm{CH}_{3}$ chain ends would not sense the $\mathrm{NH}_{3}{ }^{+}$and $\mathrm{CO}_{2}{ }^{-}$head group functionalities of the triple cation or $\mathrm{CsPBrr}_{3}$ nanocrystal surfaces with these measurements. However, intramolecular correlations measured from the triple cation system (see Fig. 6c) such as $\mathrm{CH}_{3}$ (octylamine; $\delta 0.6 \mathrm{ppm}$ ) $/ \alpha-\mathrm{CH}_{2}$ (octylamine; $\delta 3.3 \mathrm{ppm}$ ) and $\mathrm{CH}_{3}$ (octylamine; $\delta 0.6 \mathrm{ppm}$ ) $/ \mathrm{NH}_{3}{ }^{+}$(octylamine; $\delta 6.6 \mathrm{ppm}$ ) provide direct evidence for dipolar contact between the octylamine $\mathrm{CH}_{3}$ chain end and its polar head group. The only arrangement facilitating these correlations in the $2 \mathrm{D}^{1} \mathrm{H}^{-}{ }^{1} \mathrm{H}$ NOESY data is when the octylamine folds back on itself towards the nanocrystal surface as depicted in Fig. $7 \mathrm{~d}$, promoting a highly 
disordered and entangled coverage of the triple cation nanocrystal surfaces by the passivation layer. From Fig. $7 \mathrm{~d}$ a similar yet more pronounced arrangement is observed for the oleic acid passivation of the $\mathrm{CsPbBr}_{3}$ nanocrystal surface. Since octylamine dominates the surface passivation on the triple cation nanocrystal surfaces, a clearer representation of the oleic acid behavior is provided by the $2 \mathrm{D}{ }^{1} \mathrm{H}-{ }^{1} \mathrm{H}$ NOESY data from the $\mathrm{CsPbBr}_{3}$ nanocrystal surface shown in Fig. S7b-e (ESI $\left.\$\right)$ where a near-equimixture of the octylamine and oleic acid species exist. These features demonstrate that mid-points of the oleic chain interact with regions near the nanocrystal surface as illustrated in Fig. $7 d$ indicating that a highly folded and entangled arrangement again emerges.

\section{Photophysical properties}

The reported photophysical data of Fig. 8a and Table 2 show that the as-synthesized triple cation nanocrystals were highly luminescent under UV excitation and exhibit a high PLQY. As summarized in Table 2, purified samples of the $0 \mathrm{~mol} \% \mathrm{Cs}$, $5 \mathrm{~mol} \% \mathrm{Cs}, 10 \mathrm{~mol} \% \mathrm{Cs}$ and $15 \mathrm{~mol} \%$ Cs preparations display $80 \%, 93 \%, 85 \%$ and $82 \%$ PLQY, respectively, corresponding to the average carrier lifetime data of 11.7, 14.5, 13.5 and $11.6 \mathrm{~ns}$ as detailed in Fig. S8 (ESI $\ddagger$ ). The increase in carrier lifetime (and thus increased exciton survival lifetime) measured for the $5 \mathrm{~mol} \%$ Cs sample indicates the suppression of non-radiative pathways and a concomitant enhancement of the radiative channels in this sample associated with the increase in the observed PLQY. Indeed, the PLQY is proportional to the radiative lifetime $\left(\tau_{\mathrm{r}}\right)$, hence perovskite quantum dots with a high PLQY can be realized when the radiative recombination pathways are increased. ${ }^{63,64}$

These properties directly correlate with specific structural elements identified by the solid state NMR study. In particular, as the particle size decreases the ${ }^{133}$ Cs MAS NMR data reveals the emergence of an upfield ${ }^{133} \mathrm{Cs}$ shift that identifies welldefined surface/subsurface $\mathrm{Cs}^{+}$cation positions populating nanocrystal surface of the $5 \mathrm{~mol} \%$ Cs composition. These surface $\mathrm{Cs}^{+}$cation positions display noticeably longer (and field dependent) $T_{1}$ relaxation properties in comparison to those predisposed towards the nanocrystal core. As discussed above, the increased $\mathrm{Cs}^{+}$surface population and concomitant surface passivation induces an overall increased environmental stability and reduced ionic migration that is characterized by longer $T_{1}$ relaxation values. Only the $5 \mathrm{~mol} \%$ Cs triple cation composition exhibits the occurrence of these clearly resolved ${ }^{133} \mathrm{Cs}$ shifts in significant concentrations, and this distinctly partitioned $T_{1}$ behavior. Previous work has postulated that increased populations of surface/subsurface $\mathrm{Cs}^{+}$cation species are associated with improved surface passivation and environmental stability, which can yield higher PLQYs and longer carrier lifetimes. ${ }^{35,37,40,48}$

While these characteristics rationalise the trend of increased carrier lifetimes, PLQYs and overall performance of the $5 \mathrm{~mol} \%$ Cs preparation in relation to the other triple cation samples within the series, they do not explain the absolute increase in performance of the triple cation series in comparison to the $\mathrm{CsPbBr}_{3}$ nanocrystals. Other factors need to be considered to account for the absolute difference in performance between these systems. As observed in Fig. S9 (ESI $\ddagger$ ), the $\mathrm{CsPbBr}_{3}$ nanocrystals exhibit a PL peak at $516 \mathrm{~nm}$ with PLQY of $\sim 50 \%$, and the LEDs based on these nanocrystals exhibit an EQE of $2.5 \%$ which represents a lower performance in comparison to the triple cation analogues reported Table 2. The lower PLQY and device performance can be attributed to the higher framework $\mathrm{Br}^{-}$and $\mathrm{Cs}^{+}$cation vacancy concentrations present on the surface of the $\mathrm{CsPbBr}_{3}$ nanocrystals, as reported by recent computational and electric field driven ion migration studies focusing on $\mathrm{Br}^{-}$and $\mathrm{Cs}^{+}$migration dynamics. ${ }^{32,59}$ Most importantly, the $1 \mathrm{D}{ }^{13} \mathrm{C}$ and ${ }^{1} \mathrm{H}$ MAS NMR, and 2D ${ }^{1} \mathrm{H}$ MAS NMR studies described in Fig. 4-7 and Fig. S7 (ESI $\$$ ) clearly suggest that a large negative charge resides on the triple cation nanocrystal surfaces facilitating a predominance of the shorter and more conductive octylamine as the passivation ligand. These data confirm that an octylamine:oleic acid ratio of $\sim 5: 1-6: 1$ exists throughout the triple cation series in comparison to an octylamine: oleic acid ratio of $\sim 1.4: 1$ for $\mathrm{CsPbr}_{3}$ nanocrystals. In addition to the presence of surface/subsurface $\mathrm{Cs}^{+}$cation species being associated with improved surface passivation (as discussed above), the exposed (abundant) $\mathrm{Br}^{-}$ framework species on the curved triple cation nanocrystal surface are also stabilized through multiple ionic associations to the disordered network of abundant octylamine $\mathrm{NH}_{3}{ }^{+}$ head groups, as depicted in the schematic description of Fig. 7a. Furthermore, the approximate nearest-neighbour $\mathrm{Br}^{-}$ site migration distances between vacancy/defect positons on the $\mathrm{CsPbBr}_{3}$ nanocrystal surface involves hops of $\sim 5.88 / 4.15 \AA$, however same process on the triple cation nanocrystal surface is estimated to occur across longer distances of $\sim 5.98 / 4.23 \AA$ making this a less probable event, thus enabling longer carrier lifetimes and suppression of non-radiative pathways for improved PLQYs. An alteration of the surface passivation composition could stimulate increased conduction and higher LED efficiencies in the devices based on the triple cation nanocrystals in comparison to the $\mathrm{CsPbBr}_{3}$ nanocrystals-based devices (see Table 1).

Table 2 The device statistics for all fabricated LEDs. The maximum and average values are given for each device

\begin{tabular}{|c|c|c|c|c|c|c|c|}
\hline $\begin{array}{l}\text { Sample } \\
\text { name }\end{array}$ & $\begin{array}{l}\text { PLQY } \\
(\%)\end{array}$ & $\begin{array}{l}\text { No. of } \\
\text { devices }\end{array}$ & $\begin{array}{l}\text { Turn on } \\
\text { voltage }\left[V_{\mathrm{t}}\right]\end{array}$ & $\begin{array}{l}\text { Peak luminance } \\
{\left[\mathrm{cd} \mathrm{m}^{-2}\right]}\end{array}$ & $\begin{array}{l}\text { Current efficiency } \\
{\left[\mathrm{cd} \mathrm{A}^{-1}\right]}\end{array}$ & $\begin{array}{l}\text { Luminous power } \\
\text { efficiency }\left[\operatorname{lm} \mathrm{W}^{-1}\right]\end{array}$ & $\mathrm{EQE}[\%]$ \\
\hline $0 \mathrm{~mol} \% \mathrm{Cs}$ & 80 & 8 & $2.04[2.06]$ & 10218 [9243] & $12.74[11.48]$ & $14.64[12.82]$ & $3.12[2.81]$ \\
\hline $5 \mathrm{~mol} \% \mathrm{Cs}$ & 93 & 8 & $1.98[2.01]$ & $10742\left[\begin{array}{ll}10 & 056\end{array}\right]$ & $30.00[26.65]$ & $34.87[30.38]$ & $7.36[6.52]$ \\
\hline $10 \mathrm{~mol} \% \mathrm{Cs}$ & 85 & 7 & $2.05[2.11]$ & $5240[3400]$ & $24.62[22.15]$ & $27.84[24.51]$ & $5.92[5.31]$ \\
\hline $15 \mathrm{~mol} \% \mathrm{Cs}$ & 82 & 7 & $2.10[2.20]$ & $2159[1830]$ & $20.91[19.17]$ & 21.58 [19.51] & $5.14[4.73]$ \\
\hline
\end{tabular}


Additional consideration also needs to be given to the consequences of the $\mathrm{MA}^{+}$and $\mathrm{FA}^{+}$cation dynamics which participate in ultra-fast anisotropic reorientation which are attributes that are absent in the $\mathrm{CsPbBr}_{3}$ system. Quasi elastic neutron scattering, GHz spectroscopy, ${ }^{14} \mathrm{~N}$ NMR and electron diffraction studies have measured this phenomenon with the resulting reorientation times $\left(\tau_{\text {rot }}\right)$ residing in the picosecond range. ${ }^{62,65-69}$ Computational and modelling studies focusing on the $\mathrm{MA}^{+}$cation motion have demonstrated that these fast molecular rotations lead to dynamic modulation of the band structure, with the anisotropic reorientation increasing electronic contact (orbital overlap) with the lead halide cages consequently promoting a larger polaron formation. ${ }^{70}$ In turn, this enhances the radiative recombination process and thus inducing superior conversion efficiencies and PLQYs.

Fig. $8 \mathrm{~b}$ describes the absorption and emission characteristics of the as-synthesized triple cation nanocrystals dispersed in hexane; these data show a marginal blue shift in absorption edge with increasing $\mathrm{Cs}^{+}$incorporation into the cation inventory, similar to that reported for other perovskite systems. ${ }^{10,41,62,71}$ The PL peak position also shifted to the blue spectral region from $525-518 \mathrm{~nm}$ as the Cs content increased from $0 \mathrm{~mol} \%$ to $15 \mathrm{~mol} \%$, although this observation is somewhat mitigated by the subtle and monotonic corresponding increase in nanocrystal diameter which would induce an opposing red shift. ${ }^{10}$ From Fig. $8 \mathrm{c}$ it can be observed that the

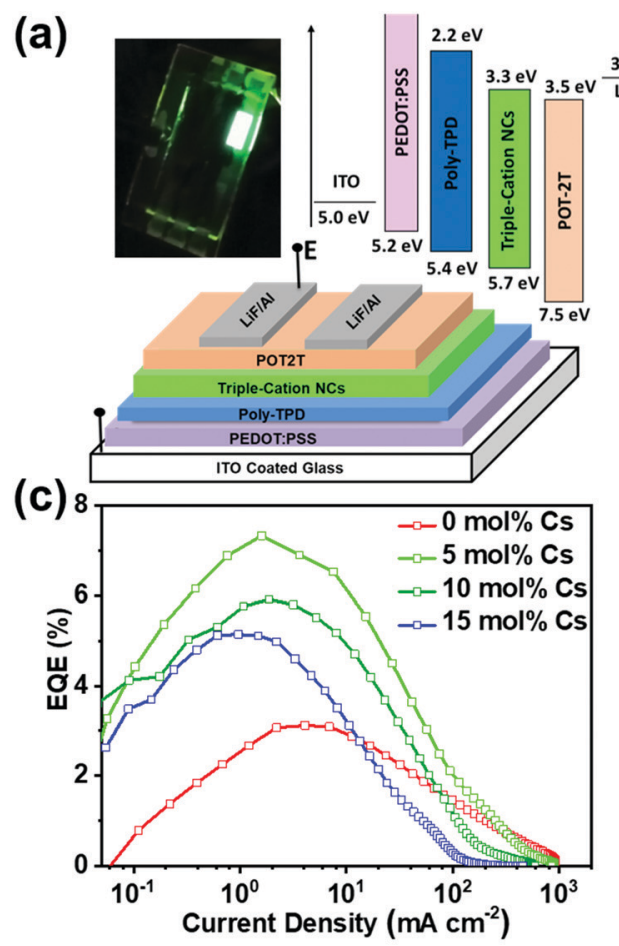

(b)

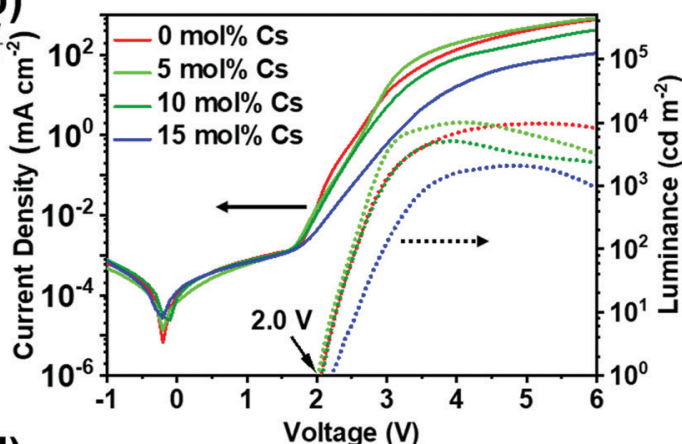

(d)
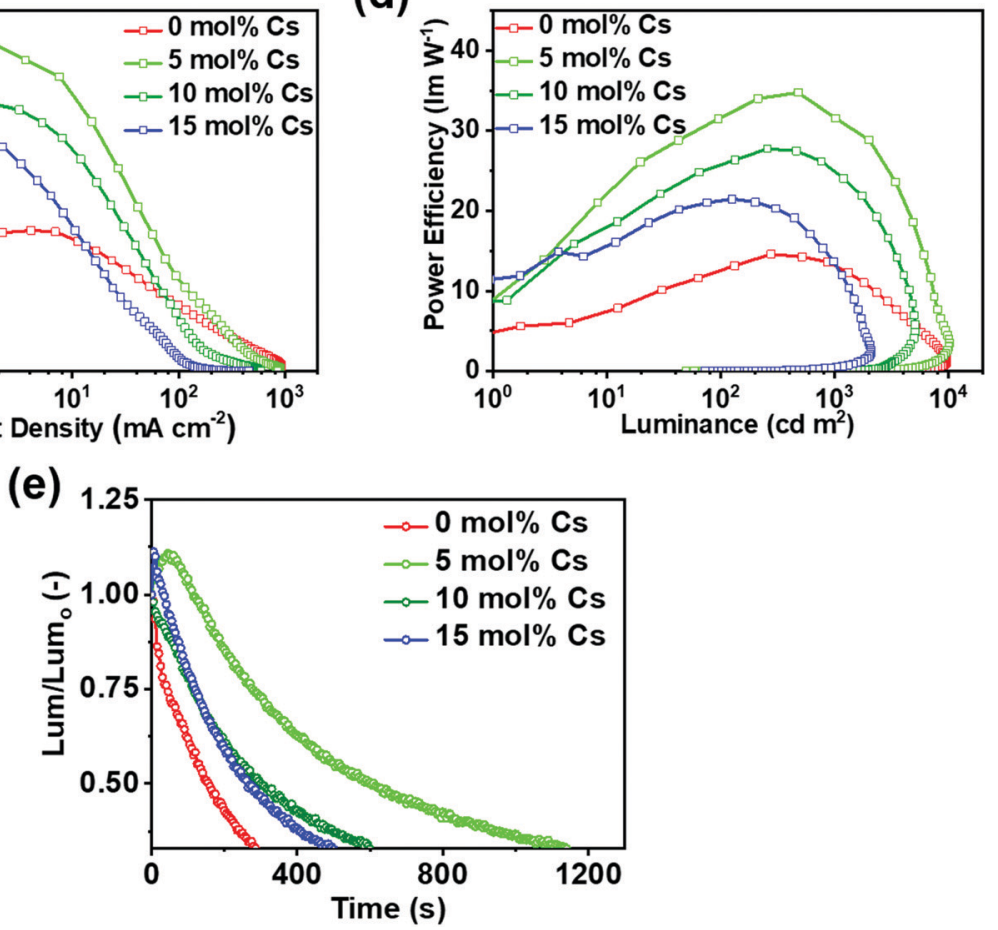

Fig. 9 The device characteristics measured from triple cation $\mathrm{Cs}_{x}\left(\mathrm{MA}_{0.17} \mathrm{FA}_{0.83}\right)_{1-x} \mathrm{PbBr}_{3}(x=0-0.15)$ series depicting, (a) a schematic diagram and energy comparison of the LED device structure along with a photograph of $5 \mathrm{~mol} \%$ Cs LED operated at $3.00 \mathrm{~V}$, (b) a plot of current density versus voltage demonstrating that these devices were characterized by low turn-on voltages of $\sim 2.0 \mathrm{~V}$, (c) a plot of EQE versus current density, (d) a plot of power efficiency vs. luminance, and (e) a study of the device stability at constant current density represented as normalized luminance (Lum/Lumo) as a function of time. For the latter study, the Lumo measurements for the $0 \mathrm{~mol} \%, 5 \mathrm{~mol} \%, 10 \mathrm{~mol} \%$ and $15 \mathrm{~mol} \%$ samples were $77.4,97.7,107.4$ and $110.1 \mathrm{~cd} \mathrm{~m}^{-2}$, respectively. These Cs-containing devices demonstrate significantly higher device stability with the 5 mol\% Cs device exhibiting the highest stability under constant current density. 
triple cation nanocrystals revealed promising photostability up to $5 \mathrm{~h}$ with constant illumination $(\lambda=350 \mathrm{~nm})$, with the first $2 \mathrm{~h}$ of constant illumination showing no indication of peak shifts and intensity changes. Under ambient conditions, the triple cation samples were also found to be stable in colloidal suspensions for up to $\sim 30$ days, while the non-Cs containing samples were comparatively less stable in similar suspensions and were viable for only $\sim 10$ days. These narrow emission line width, high PLQY and photostability characteristics demonstrate that this material is a suitable candidate for LED applications.

Green-emitting LEDs were fabricated from purified nanocrystals stably dispersed in hexane. The LED device structure comprised: indium tin oxide (ITO)/poly(3,4-ethylenedioxythiophene) polystyrene sulfonate (PEDOT:PSS, $45 \mathrm{~nm}$ )/poly(4butylphenyl-diphenyl-amine) (Poly-TPD, $30 \mathrm{~nm}$ )/NCs (45 nm)/ 2,4,6-tris[3-(diphenylphosphinyl)phenyl]-1,3,5-triazine (POT2T, $45 \mathrm{~nm}) / \mathrm{LiF}(0.8 \mathrm{~nm}) / \mathrm{Al}(80 \mathrm{~nm})$ respectively. PEDOT:PSS and poly-TPD served as a hole injecting layers, while POT2T was an electron injecting layer. A detailed description of the device fabrication process is given in the ESI. $\neq$ The schematic and energy diagram of the LED device structure is presented in Fig. 9a. While energy levels for the organic transport layers were obtained from literature values, ${ }^{5,39}$ the energy levels of $5 \mathrm{~mol} \%$ Cs nanocrystals were estimated from photoelectron spectroscopy (PESA) measurements reported in Fig. S10 (ESI $\ddagger$ ).

The LEDs show bright green emission (i.e. in the 520$530 \mathrm{~nm}$ spectral region) with a narrow emission linewidth $($ FWHM $=19 \mathrm{~nm})$. The inset of Fig. 9a shows LEDs fabricated using the $5 \mathrm{~mol} \%$ Cs sample at $3 \mathrm{~V}$. A marginal red shift of a few nanometres was observed between the electroluminescence (EL) and PL spectra due to the transition from solution to thinfilms, wherein Förster resonance energy transfer (FRET) takes place to lower the band gap between neighboring nanocrystals within $\sim 1 \mathrm{~nm}$ (see Fig. S11a, ESI $\$$ ). ${ }^{72}$ As demonstrated in Fig. 9b, all devices exhibit standard diode characteristics with low leakage current and very low turn-on voltages in the range of $2.0-2.1 \mathrm{~V}$, which is minimized in $5 \mathrm{~mol} \%$ Cs sample. The paired maximum luminance and maximum luminance at peak EQE values were 9662; $276 \mathrm{~cd} \mathrm{~m}^{-2}, 10207 ; 474 \mathrm{~cd} \mathrm{~m}^{-2}, 5100$; $460 \mathrm{~cd} \mathrm{~m}^{-2}$ and 2090; $201 \mathrm{~cd} \mathrm{~m}^{-2}$ measured from the $0 \mathrm{~mol} \%$ Cs, $5 \mathrm{~mol} \% \mathrm{Cs}, 10 \mathrm{~mol} \% \mathrm{Cs}$ and $15 \mathrm{~mol} \% \mathrm{Cs}$ samples, respectively (see Fig. 9b and Fig. S11b, ESI $\$$ ). Fig. 9c shows plots of EQE $v s$. current density for each device, where the EQE increases rapidly and significantly above their turn-on voltage, with roll-off at higher current density. Efficiency roll-off at higher current density is due to Auger recombination. ${ }^{73,74}$ Overall, the $0 \mathrm{~mol} \% \mathrm{Cs}, 5 \mathrm{~mol} \% \mathrm{Cs}, 10 \mathrm{~mol} \% \mathrm{Cs}$ and $15 \mathrm{~mol} \%$ Cs nanocrystal systems deliver maximum EQEs (current efficiencies) of $3.12 \%\left(12.53 \mathrm{~cd} \mathrm{~A} \mathrm{~A}^{-1}\right), 7.36 \%\left(30.01 \mathrm{~cd} \mathrm{~A} \mathrm{~A}^{-1}\right)$, $5.92 \%\left(24.52 \mathrm{~cd} \mathrm{~A}^{-1}\right.$ ) and 5.14\% (20.81 $\mathrm{cd} \mathrm{A}^{-1}$ ), respectively (see Fig. 9c and Fig. S11c, ESI $\$$ ). From Fig. 9d, a plots of luminous power efficiency $v s$. luminance displayed indicates that the device employing $5 \mathrm{~mol} \%$ Cs displays the maximum power efficiency of $34.76 \mathrm{~lm} \mathrm{~W}^{-1}$ at $478 \mathrm{~cd} \mathrm{~m}^{-2}$, with a minimum power efficiency of $14.58 \mathrm{~lm} \mathrm{~W}^{-1}$ at $276 \mathrm{~cd} \mathrm{~m}^{-2}$ of luminance characterizing the $0 \mathrm{~mol} \%$ Cs device.
The performance metrics for all LEDs are listed in Table 2. The trend in LED efficiency is in agreement with PLQY and carrier lifetime data. As a small amount of dibenzo-21-crown-7ether was used in the triple cation nanocrystal synthesis, it was pertinent to rule out any effect of this component on the device efficiency. LED devices were fabricated using the $0 \mathrm{~mol} \% \mathrm{Cs}$ product with and without the incorporation of crown ether; from this comparison no noticeable improvement in device performance was observed (see Fig. S12 and Table S3, ESI $\ddagger$ ). This test concludes that the highest EQE achieved from the $5 \mathrm{~mol} \% \mathrm{Cs}$ LED can be attributed to the incorporation of an optimum $5 \mathrm{~mol} \% \mathrm{Cs}$ content into the nanocrystal structure. Furthermore, as demonstrated in Fig. 9e, devices prepared from Cs-containing triple cation nanocrystals displayed improved stability at constant current density, with the $5 \mathrm{~mol} \%$ Cs device revealing the highest stability at a constant current density of $1.58 \mathrm{~mA} \mathrm{~cm}^{-2}$. In particular, the $5 \mathrm{~mol} \%$ Cs device displays a two-fold increase in current stability in comparison the other triple cation devices, corroborating the increased $\mathrm{Cs}^{+}$passivation and surface environmental stability in this sample. ${ }^{23,73}$ Nonetheless, a detailed micro-level analysis is warranted to completely investigate the device mechanism for each sample. From Fig. S11d (ESI ), all these devices show EL peak stability under the applied electric field, which is a crucial factor for future perovskite LED commercialization. It should be noted that no further surface passivation schemes were explored in addition to the octylamine/oleic nanocrystal capping reported here in order to investigate improved conduction properties. Nevertheless, future research will entail the additional optimization of numerous aspects to enhance the device performance. For instance, the implementation of an 'n-i-p' device structure and the use of metal nanocrystals in perovskite active layer solutions to enable localized surface plasmon effects were found to be an effective way to improve the EQE and perovskite LED stability. ${ }^{75,76}$

\section{Conclusion}

This study has described the development of a high performance Cs-containing triple cation perovskite nanocrystal system for optoelectronic applications. The room temperature synthesis of triple cation nanocrystals of nominal stoichiometry $\mathrm{Cs}_{x}\left(\mathrm{MA}_{0.17} \mathrm{FA}_{0.83}\right)_{1-x} \mathrm{PbBr}_{3}(x=0-0.15)$ was demonstrated, and this new system was able to deliver high PLQY of up to $\sim 93 \%$ while maintaining excellent photostability under continuous UV illumination. An optimized NC purification process performed to obtain high quality nanocrystals ink for LED fabrication. The resultant LEDs displayed green-emitting characteristics, with a maximum EQE of $7.4 \%\left(30 \mathrm{~cd} \mathrm{~A}^{-1}\right)$ corresponding to a power efficiency of $34.87 \mathrm{~lm} \mathrm{~W}^{-1}$ being achieved from the compositionally optimized $\mathrm{Cs}_{0.05}\left(\mathrm{MA}_{0.17^{-}}\right.$ $\left.\mathrm{FA}_{0.83}\right)_{0.95} \mathrm{PbBr}_{3}$ (5 mol\% Cs) triple cation system. Although the $5 \mathrm{~mol} \%$ Cs nanocrystal sample was the best performing composition, all samples comprising this suite exhibited improved operational characteristics over the more established 
$\mathrm{CsPbBr}_{3}$ nanocrystal system. In contrast to the cubic morphology characterizing $\mathrm{CsPbBr}_{3}$ nanocrystals, the triple cation nanocrystal morphology is dominated by spherical particles that exhibit increased thermal stability and durability under the TEM-EDXS beam, and with the specific size range being sensitive to the amount of Cs incorporation.

A multinuclear solid state ${ }^{133} \mathrm{Cs},{ }^{207} \mathrm{~Pb}{ }^{1} \mathrm{H}$ and ${ }^{13} \mathrm{C}$ MAS NMR study reveals significant structural disorder within the A-site cation $\left(\mathrm{Cs}^{+}, \mathrm{FA}^{+}\right.$and $\left.\mathrm{MA}^{+}\right)$species, and within the octylamine and oleic acid agents passivating the nanocrystal surface, despite the highly ordered $\mathrm{PbBr}_{6}{ }^{4-}$ perovskite framework underpinning the overall structure (space group $P m \overline{3} m$, $a=5.984-5.944 \AA$ ). The TEM-EDXS and ${ }^{133}$ Cs MAS NMR studies suggest that the $\mathrm{Cs}^{+}$cations are dispersed heterogeneously throughout the spherical nanocrystals; this dispersion appears concentration and particle size dependent. While the Cs speciation is essentially partitioned towards the centre of the larger diameter/higher Cs content (15 mol\% Cs) nanocrystals in a 'pseudo-core-shell' arrangement, the data from smaller diameter/lower Cs concentration systems (i.e. $10 \mathrm{~mol} \% \mathrm{Cs}$ and $5 \mathrm{~mol} \% \mathrm{Cs}$ ) demonstrates an increasing sensitivity to the particle surface with additional upfield (lower ppm) ${ }^{133} \mathrm{Cs}$ resonances being observed. These findings suggest a gradual departure from the 'pseudo-core-shell' configuration as the nanocrystal diameter decreases, with the $5 \mathrm{~mol} \%$ Cs preparation demonstrating the emergence of substantial populations of surface and sub-surface $\mathrm{Cs}^{+}$cation positions characterized by resolved upfield ${ }^{133} \mathrm{Cs}$ chemical shifts and highly partitioned $T_{1}$ behavior. This study provides the first solid state NMR evidence linking improved functional properties such as higher PLQYs and surface carrier lifetimes with increased surface passivation and environmental stability, as evidenced by the longer $T_{1}$ relaxation of the surface $\mathrm{Cs}^{+}$speciation in the $5 \mathrm{~mol} \% \mathrm{Cs}$ system suggesting slower migration dynamics in comparison to the core $\mathrm{Cs}^{+}$positions.

The corresponding $1 \mathrm{D}$ and $2 \mathrm{D}^{1} \mathrm{H}$ and ${ }^{13} \mathrm{C}$ MAS NMR studies demonstrates that the relative $\mathrm{FA}^{+}: \mathrm{MA}^{+}$ratio of $\sim 4: 1$ in the initial reaction is maintained throughout this nanocrystal series in close association with the initial nominal stoichiometry. Furthermore, the octylamine surface passivation agent exhibits a far greater binding affinity to the triple cation nanocrystal surface than its oleic acid counterpart (i.e. octylamine: oleic acid $\sim 6: 1$ on average throughout the series), despite the $\sim 20: 1$ predominance of oleic acid in the precursor mixture. This observation contrasts markedly with similar measurements characterizing the $\mathrm{CsPBr}_{3}$ nanocrystal surface that shows the support of a near equi-mixture of octylamine and oleic acid ( $\sim 1.4: 1$ ratio). These studies also conclusively prove that other organic solvents such as dibenzo-21crown-7-ether, DMF and toluene are not transferred from reaction mixtures onto the triple cation and $\mathrm{CsPbBr}_{3}$ nanocrystal surfaces. Although, the crown ether is detected in trace quantities $(<1 \%)$ it plays no functional role on the surface of either nanocrystalline material. The octylamine dominance suggests that the triple cation nanocrystal surface carries a large negative charge via the exposure of $\mathrm{Br}^{-}$positions on the disordered spherical particle surface. More complex 2D homonuclear ${ }^{1} \mathrm{H}-{ }^{1} \mathrm{H}$ NOESY measurements show strong intermolecular FA-octylamine and MA-octylamine correlations to sparse $\mathrm{FA}^{+}$and $\mathrm{MA}^{+}$cation surface populations, and much greater $\mathrm{FA}^{+}$and $\mathrm{MA}^{+}$sub-surface populations. More importantly, these data also reveal additional correlations that show the local structures of both passivation ligands do not radiate outward from the particle core, but instead fold back towards the nanocrystal surface thus contributing further to the intrinsic disorder of both the triple cation and $\mathrm{CsPbBr}_{3}$ nanocrystal surfaces.

While the superior photophysical properties of the $5 \mathrm{~mol} \%$ Cs system in comparison to the other triple cation preparations with higher $\mathrm{Cs}^{+}$cation concentrations can be rationalized in terms of increased surface passivation and reduced $\mathrm{Cs}^{+}$ migration, the superior performance of the triple cation nanocrystal series over its $\mathrm{CsPbBr}_{3}$ counterparts is explained in terms of other contributing factors. As evidenced by the $1 \mathrm{D}$ ${ }^{13} \mathrm{C}$ and ${ }^{1} \mathrm{H}$ MAS NMR, and $2 \mathrm{D}{ }^{1} \mathrm{H}$ MAS NMR studies indicate that a large negative charge resides on the triple cation nanocrystal surfaces facilitating a predominance of the shorter and more conductive octylamine passivation ligand. These characteristics are coupled with the ultra-fast anisotropic reorientation dynamics of the $\mathrm{MA}^{+}$and $\mathrm{FA}^{+}$cations (absent in the $\mathrm{CsPbBr}_{3}$ system) which can induce larger polaron formation, enhanced readiative recombination and superior PLQYs to yield the reported improvements of in this work. Since this study represents the first investigation of triple cation nanocrystal systems, a broadened synthesis strategy is expected to drive improvements in device performance. Further studies will alter the ligand exchange process in order to improve the surface passivation of the nanocrystals, and the conductivity of the nanocrystal thin films. Other approaches could involve the incorporation of different halides (i.e. $\mathrm{Cl}$ or I), or novel mixed halide $\mathrm{Cl} / \mathrm{Br}, \mathrm{Br} / \mathrm{I}$ triple cation combinations, to stimulate the further tuning of the band gap and emission properties of these nanocrystals for LEDs applications. These materials are also suitable for solar cell applications where hole-transport from the photo absorber perovskite film to the metal electrode can be facilitated. Hence, the nanocrystal series detailed herein could promote a wide range of possibilities towards numerous optoelectronic applications.

\section{Experimental}

\section{Materials}

Cesium bromide (99.999\% trace metal basis), $\mathrm{PbBr}_{2}$ (99.999\% trace metal basis, Aldrich), dibenzo-21-crown-7 ether (97\%, Aldrich), $\mathrm{PbI}_{2}$ (99.999\%, trace metal basis), MABr (Greatcellsolar), $\mathrm{FABr}$ (Greatcellsolar), $\mathrm{N}, \mathrm{N}$-dimethylformamide (anhydrous, 99.8\%, Aldrich), toluene (anhydrous, 99.8\%, Aldrich), hexane (anhydrous, 95\%, Aldrich), octylamine (99\%, Aldrich), and oleic acid (technical grade, 90\%, Aldrich).

\section{Synthesis}

Triple cation nanocrystals incorporating 0, 5, 10 and $15 \mathrm{~mol} \%$ Cs were prepared using a ligand assisted re-precipitation method (LARP) method. ${ }^{35,45-49}$ A precursor solution containing 
$\mathrm{CsBr}, \mathrm{FABr}$ and $\mathrm{MABr}$ (total of $0.1 \mathrm{mmol}), \mathrm{PbBr}_{2}(0.1 \mathrm{mmol})$ and dibenzo-21-crown-7-ether (same mmol as $\mathrm{CsBr}$ ) was prepared in $1 \mathrm{ml}$ of DMF in argon filled glove box at room temperature. The molar ratio between $\mathrm{Cs}$ and $\left(\mathrm{FA}_{0.83} \mathrm{MA}_{0.17}\right)$ was varied from $0: 1$ to $0.15: 0.85$ (see Table S1, ESI $\$$ ). $150 \mu \mathrm{l}$ of the precursor solution was added dropwise into a solution containing $5 \mathrm{ml}$ toluene, $21 \mu \mathrm{l}$ octylamine and $474 \mu \mathrm{l}$ oleic acid under continuous stirring in ambient conditions. The NCs were instantly precipitated and a bright green-yellow solution was obtained. After the reaction was completed, the NCs were centrifuged at $10000 \mathrm{rpm}$ for $12 \mathrm{~min}$. The resulting supernatant phase was discarded and the precipitate was re-dispersed in $250 \mu$ hexane followed by further centrifugation at $1000 \mathrm{rpm}$ for $12 \mathrm{~min}$. The resultant supernatant was used for further characterization and device fabrication as a NC ink. In order to get a high NC ink concentration, 5 to 6 separate reactions were performed and merged during the washing process.

A similar LARP methodology was adopted to synthesize pure $\mathrm{CsPbBr}_{3}$ nanocrystals, where a $0.1 \mathrm{mmol}$ mixture of $\mathrm{CsBr}$ and $\mathrm{PbBr}_{2}$, with $0.1 \mathrm{mmol}$ of dibenzo-21-crown-[7] ether, were dissolved in $1 \mathrm{ml}$ of DMF. $150 \mu \mathrm{l}$ of this precursor solution was added drop-wise into a $5 \mathrm{ml}$ solution containing toluene, oleic acid and octylamine under stirring. The average size of these nanoparticles was determined to be $\sim 11 \mathrm{~nm}$ from HR-TEM analysis (see Fig. S1e, ESI $\ddagger$ ), which is also a typical size of $\mathrm{CsPbBr}_{3}$ nanocrystals synthesized using a conventional (hot-injection) method. ${ }^{10,32}$ All details describing the nanocrystal characterization, and LED fabrication and measurement, can be found in the ESI.+

\section{Author contributions}

P. V., S. A. V., S. G. M. and J. V. H. designed the initial experiments related to the material synthesis, device fabrication and characterisation. P. V. performed all the synthesis, XRD and TEM characterization, optical measurements, and device fabrication. Valuable assistance for the optical measurements was given by M. S. A., A. B., N. M., and A. A. M. B. and for the crystallographic analyses was given by Y. F. and T. W. J. V. H. designed and guided the all solid state MAS NMR measurements pertaining to the surface and bulk structural characterisation, with experimental and data processing contributions coming from S. H. D., N. L. K. and B. E. G., J. V. H. and $\mathrm{P}$. V. wrote the manuscript and all authors viewed it and contributed to its content. S. G. M., T. W., P. V., and J. V. H. secured the necessary funding for this study.

\section{Conflicts of interest}

There are no conflicts to declare.

\section{Acknowledgements}

PV acknowledges a Presidential Postdoctoral Fellowship from Nanyang Technological University (NTU), Singapore via grant
M408070000, and SGM, TW and SSHD acknowledge financial support from the Singapore National Research Foundation, Prime Minister's Office, through the Competitive Research Program (CRP Award No. NRF-CRP14-2014-03). NLK thanks EPSRC for a PhD studentship through the EPSRC Centre for Doctoral Training in Molecular Analytical Science (EP/L015307/1). The authors would like to acknowledge the Facility for Analysis, Characterization, Testing and Simulation (FACTS) at NTU, Singapore, for use of their electron microscopy and X-ray diffraction facilities. The authors would also like to thank Dr Bahulayan Damodaran for helpful discussions and assistance. JVH acknowledges financial support for the solid state NMR instrumentation at Warwick used in this research which was funded by EPSRC (grants EP/M028186/1 and EP/K024418/1), the University of Warwick, and the Birmingham Science City AM1 and AM2 projects which were supported by Advantage West Midlands (AWM) and the European Regional Development Fund (ERDF).

\section{References}

1 D. V. Talapin, J.-S. Lee, M. V. Kovalenko and E. V. Shevchenko, Chem. Rev., 2010, 110, 389-458.

2 J. Huang, Y. Yang, S. Xue, B. Yang, S. Liu and J. Shen, Appl. Phys. Lett., 1997, 70, 2335-2337.

3 I. Robel, M. Kuno and P. V. Kamat, J. Am. Chem. Soc., 2007, 129, 4136-4137.

4 S. Mehra, S. Bishnoi, A. Jaiswal, M. Jagadeeswararao, A. K. Srivastava, S. N. Sharma and P. Vashishtha, Energy Storage, 2019, e120.

5 P. O. Anikeeva, J. E. Halpert, M. G. Bawendi and V. Bulovic, Nano Lett., 2009, 9, 2532-2536.

6 W. Zou, Z.-j. Du, H.-q. Li and C. Zhang, J. Mater. Chem., 2011, 21, 13276-13282.

7 Z.-S. Guo, L. Zhao, J. Pei, Z.-L. Zhou, G. Gibson, J. Brug, S. Lam and S. S. Mao, Macromolecules, 2010, 43, 1860-1866.

8 O. I. Mićić, J. Sprague, Z. Lu and A. J. Nozik, Appl. Phys. Lett., 1996, 68, 3150-3152.

9 H. Zhong, S. S. Lo, T. Mirkovic, Y. Li, Y. Ding, Y. Li and G. D. Scholes, ACS Nano, 2010, 4, 5253-5262.

10 J. Butkus, P. Vashishtha, K. Chen, J. K. Gallaher, S. K. Prasad, D. Z. Metin, G. Laufersky, N. Gaston, J. E. Halpert and J. M. Hodgkiss, Chem. Mater., 2017, 29, 3644-3652.

11 P. Vashishtha, G. V. Nutan, B. E. Griffith, Y. Fang, D. Giovanni, M. Jagadeeswararao, T. C. Sum, N. Mathews, S. G. Mhaisalkar and J. V. Hanna, Chem. Mater., 2019, 31, 9003-9011.

12 L. Qian, Y. Zheng, J. Xue and P. H. Holloway, Nat. Photonics, 2011, 5, 543-549.

13 Y. Yang, Y. Zheng, W. Cao, A. Titov, J. Hyvonen, J. R. Manders, J. Xue, P. H. Holloway and L. Qian, Nat. Photonics, 2015, 9, 259-266.

14 J. S. Steckel, P. Snee, S. Coe-Sullivan, J. P. Zimmer, J. E. Halpert, P. Anikeeva, L. A. Kim, V. Bulovic and M. G. Bawendi, Angew. Chem., Int. Ed., 2006, 45, 5796-5799. 
15 X. Dai, Z. Zhang, Y. Jin, Y. Niu, H. Cao, X. Liang, L. Chen, J. Wang and X. Peng, Nature, 2014, 515, 96-99.

16 P. Vashishtha, D. Z. Metin, M. E. Cryer, K. Chen, J. M. Hodgkiss, N. Gaston and J. E. Halpert, Chem. Mater., 2018, 30, 2973-2982.

17 V. A. Hintermayr, A. F. Richter, F. Ehrat, M. Döblinger, W. Vanderlinden, J. A. Sichert, Y. Tong, L. Polavarapu, J. Feldmann and A. S. Urban, Adv. Mater., 2016, 28, 9478-9485.

18 A. Kojima, K. Teshima, Y. Shirai and T. Miyasaka, J. Am. Chem. Soc., 2009, 131, 6050-6051.

19 H.-S. Kim, C.-R. Lee, J.-H. Im, K.-B. Lee, T. Moehl, A. Marchioro, S.-J. Moon, R. Humphry-Baker, J.-H. Yum, J. E. Moser, M. Grätzel and N.-G. Park, Sci. Rep., 2012, 2, 591.

20 Y. Rong, Y. Hu, A. Mei, H. Tan, M. I. Saidaminov, S. I. Seok, M. D. McGehee, E. H. Sargent and H. Han, Science, 2018, 361, eaat8235.

21 E. H. Jung, N. J. Jeon, E. Y. Park, C. S. Moon, T. J. Shin, T.-Y. Yang, J. H. Noh and J. Seo, Nature, 2019, 567, 511-515.

22 Y. Ma, P. Vashishtha, K. Chen, E. L. Peach, D. Ohayon, J. M. Hodgkiss and J. E. Halpert, ChemSusChem, 2017, 10, 2677-2684.

23 M. Saliba, T. Matsui, J.-Y. Seo, K. Domanski, J.-P. Correa-Baena, M. K. Nazeeruddin, S. M. Zakeeruddin, W. Tress, A. Abate and A. Hagfeldt, Energy Environ. Sci., 2016, 9, 1989-1997.

24 J. P. C. Baena, L. Steier, W. Tress, M. Saliba, S. Neutzner, T. Matsui, F. Giordano, T. J. Jacobsson, A. R. S. Kandada and S. M. Zakeeruddin, Energy Environ. Sci., 2015, 8, 2928-2934.

25 M. Saliba, S. Orlandi, T. Matsui, S. Aghazada, M. Cavazzini, J.-P. Correa-Baena, P. Gao, R. Scopelliti, E. Mosconi and K.-H. Dahmen, Nat. Energy, 2016, 1, 15017.

26 D. Bi, W. Tress, M. I. Dar, P. Gao, J. Luo, C. Renevier, K. Schenk, A. Abate, F. Giordano and J.-P. C. Baena, Sci. Adv., 2016, 2, e1501170.

27 M. Azam, S. Yue, R. Xu, K. Liu, K. Ren, Y. Sun, J. Liu, Z. Wang, S. Qu and Z. Wang, J. Mater. Chem. A, 2018, 6, 13725-13734.

28 M. Stolterfoht, C. M. Wolff, Y. Amir, A. Paulke, L. PerdigónToro, P. Caprioglio and D. Neher, Energy Environ. Sci., 2017, 10, 1530-1539.

29 C. Wang, C. Zhang, S. Wang, G. Liu, H. Xia, S. Tong, J. He, D. Niu, C. Zhou and K. Ding, Sol. RRL, 2018, 2, 1700209.

30 Y. Wang, J. Wu, P. Zhang, D. Liu, T. Zhang, L. Ji, X. Gu, Z. D. Chen and S. Li, Nano Energy, 2017, 39, 616-625.

31 P. Vashishtha, M. Ng, S. B. Shivarudraiah and J. E. Halpert, Chem. Mater., 2018, 31, 83-89.

32 P. Vashishtha and J. E. Halpert, Chem. Mater., 2017, 29, 5965-5973.

33 Z. Xiao, R. A. Kerner, L. Zhao, N. L. Tran, K. M. Lee, T.-W. Koh, G. D. Scholes and B. P. Rand, Nat. Photonics, 2017, 11, 108-115.

34 K. Lin, J. Xing, L. N. Quan, F. P. G. de Arquer, X. Gong, J. Lu, L. Xie, W. Zhao, D. Zhang and C. Yan, Nature, 2018, 562, 245-248.

35 S. A. Veldhuis, Y. F. Ng, R. Ahmad, A. Bruno, N. F. Jamaludin, B. Damodaran, N. Mathews and S. G. Mhaisalkar, ACS Energy Lett., 2018, 3, 526-531.
36 M. Yuan, L. N. Quan, R. Comin, G. Walters, R. Sabatini, O. Voznyy, S. Hoogland, Y. Zhao, E. M. Beauregard and P. Kanjanaboos, Nat. Nanotechnol., 2016, 11, 872-877.

37 G. Li, F. W. R. Rivarola, N. J. Davis, S. Bai, T. C. Jellicoe, F. de la Peña, S. Hou, C. Ducati, F. Gao and R. H. Friend, $A d v$. Mater., 2016, 28, 3528-3534.

38 F. Yan and H. V. Demir, Nanoscale, 2019, 11, 11402-11412. 39 X. Y. Chin, A. Perumal, A. Bruno, N. Yantara, S. A. Veldhuis, L. Martínez-Sarti, B. Chandran, V. Chirvony, A. S.-Z. Lo and J. So, Energy Environ. Sci., 2018, 11, 1770-1778.

40 A. A. M. Brown, T. J. N. Hooper, S. A. Veldhuis, X. Y. Chin, A. Bruno, P. Vashishtha, J. N. Tey, L. Jiang, B. Damodaran and S. H. Pu, Nanoscale, 2019, 11, 12370-12380.

41 X. Zhang, H. Liu, W. Wang, J. Zhang, B. Xu, K. L. Karen, Y. Zheng, S. Liu, S. Chen and K. Wang, Adv. Mater., 2017, 29, 1606405.

42 B. Xu, W. Cao, X. Zhang, W. Wang, J. Hao, S. Chen, K. Wang and X. Sun, Conference on Lasers and Electro-Optics (CLEO), 2017, 1-2.

43 I. Borriello, G. Cantele and D. Ninno, Phys. Rev. B: Condens. Matter Mater. Phys., 2008, 77, 235214.

44 H. P. Kim, J. Kim, B. S. Kim, H. M. Kim, J. Kim, A. R. B. M. Yusoff, J. Jang and M. K. Nazeeruddin, Adv. Opt. Mater., 2017, 5, 1600920.

45 X. Du, G. Wu, J. Cheng, H. Dang, K. Ma, Y.-W. Zhang, P.-F. Tan and S. Chen, RSC Adv., 2017, 7, 10391-10396.

46 F. Zhang, H. Zhong, C. Chen, X.-G. Wu, X. Hu, H. Huang, J. Han, B. Zou and Y. Dong, ACS Nano, 2015, 9, 4533-4542.

47 I. Levchuk, A. Osvet, X. Tang, M. Brandl, J. D. Perea, F. Hoegl, G. J. Matt, R. Hock, M. Batentschuk and C. J. Brabec, Nano Lett., 2017, 17, 2765-2770.

48 S. Bhaumik, S. A. Veldhuis, Y. F. Ng, M. Li, S. K. Muduli, T. C. Sum, B. Damodaran, S. Mhaisalkar and N. Mathews, Chem. Commun., 2016, 52, 7118-7121.

49 L. Liu, S. Huang, L. Pan, L. J. Shi, B. Zou, L. Deng and H. Zhong, Angew. Chem., Int. Ed., 2017, 56, 1780-1783.

50 L. Protesescu, S. Yakunin, M. I. Bodnarchuk, F. Krieg, R. Caputo, C. H. Hendon, R. X. Yang, A. Walsh and M. V. Kovalenko, Nano Lett., 2015, 15, 3692-3696.

51 S. Govinda, B. P. Kore, D. Swain, A. Hossain, C. De, T. N. Guru Row and D. Sarma, J. Phys. Chem. C, 2018, 122, 13758-13766.

52 A. Perumal, S. Shendre, M. Li, Y. K. E. Tay, V. K. Sharma, S. Chen, Z. Wei, Q. Liu, Y. Gao and P. J. S. Buenconsejo, Sci. Rep., 2016, 6, 36733.

53 D. T. Cromer and J. B. Mann, Acta Crystallogr., Sect. A: Cryst. Phys., Diffr., Theor. Gen. Crystallogr., 1968, 24, 321-324.

54 D. Creagh and J. Hubbell, Acta Crystallogr., Sect. A: Found. Crystallogr., 1987, 43, 102-112.

55 G. J. Rees, S. T. Orr, L. O. Barrett, J. M. Fisher, J. Houghton, G. H. Spikes, B. R. Theobald, D. Thompsett, M. E. Smith and J. V. Hanna, Phys. Chem. Chem. Phys., 2013, 15, 17195-17207.

56 T. J. Hooper, T. A. Partridge, G. J. Rees, D. S. Keeble, N. A. Powell, M. E. Smith, I. P. Mikheenko, L. E. Macaskie, P. T. Bishop and J. V. Hanna, Phys. Chem. Chem. Phys., 2018, 20, 26734-26743. 
57 T. Chen, I. Ellis, T. J. Hooper, E. Liberti, L. Ye, B. T. Lo, C. O'Leary, A. A. Sheader, G. T. Martinez, L. Jones, P. L. Ho, P. Zhao, P. J. Cookson, P. T. Bishop, P. Chater, J. V. Hanna, P. Nellist and S. C. E. Tsang, J. Am. Chem. Soc., 2019, 141, 19616-19624.

58 T. C. Farrar and E. D. Becker, Pulse and Fourier Transform NMR: Introduction to Theory and Methods, Elsevier, 2012.

59 B. B. Zhang, F. Wang, H. Zhang, B. Xiao, Q. Sun, J. Guo, A. B. Hafsia, A. Shao, Y. Xu and J. Zhou, Appl. Phys. Lett., 2020, 116, 063505.

60 J. De Roo, M. Ibáñez, P. Geiregat, G. Nedelcu, W. Walravens, J. Maes, J. C. Martins, I. Van Driessche, M. V. Kovalenko and Z. Hens, ACS Nano, 2016, 10, 2071-2081.

61 D. Neuhaus, eMagRes, 2007, 1-16.

62 T. Baikie, N. S. Barrow, Y. Fang, P. J. Keenan, P. R. Slater, R. O. Piltz, M. Gutmann, S. G. Mhaisalkar and T. J. White, J. Mater. Chem. A, 2015, 3, 9298-9307.

63 J. Shi, F. Li, J. Yuan, X. Ling, S. Zhou, Y. Qian and W. Ma, J. Mater. Chem. A, 2019, 7, 20936-20944.

64 C. H. Tien, L. C. Chen, K. Y. Lee, Z. L. Tseng, Y. S. Dong and Z. J. Lin, Energies, 2019, $12,3507$.

65 A. M. A. Leguy, J. M. Frost, A. P. McMahon, V. G. Sakai, W. Kochelmann, C. H. Law, X. E. Li, F. Foglia, A. Walsh, B. C. O'Regan, J. Nelson, J. T. Cabral and P. R. F. Barnes, Nat. Commun., 2015, 6.

66 D. H. Fabini, T. A. Siaw, C. C. Stoumpos, G. Laurita, D. Olds, K. Page, J. G. Hu, M. G. Kanatzidis, S. Han and R. Seshadri, J. Am. Chem. Soc., 2017, 139, 16875-16884.
67 X. Wu, L. Z. Tan, X. Shen, T. Hu, K. Miyata, M. T. Trinh, R. Li, R. Coffee, S. Liu, D. A. Egger, I. Makasyuk, Q. Zheng, A. Fry, J. S. Robinson, M. D. Smith, B. Guzelturk, H. I. Karunadasa, X. Wang, X. Zhu, L. Kronik, A. M. Rappe and A. M. Lindenberg, Sci. Adv., 2017, 3, e1602388.

68 G. M. Bernard, R. E. Wasylishen, C. I. Ratcliffe, V. Terskikh, Q. Wu, J. M. Buriak and T. Hauger, J. Phys. Chem. A, 2018, 122, 1560-1573.

69 D. J. Kubicki, D. Prochowicz, A. Pinon, G. Stevanato, A. Hofstetter, S. M. Zakeeruddin, M. Gratzel and L. Emsley, J. Mater. Chem. A, 2018, 7, 2326-2333.

70 C. Motta1, F. El-Mellouhi, S. Kais, N. Tabet, F. Alharbi and S. Sanvito, Nat. Commun., 2014, 1.

71 L. Protesescu, S. Yakunin, M. I. Bodnarchuk, F. Bertolotti, N. Masciocchi, A. Guagliardi and M. V. Kovalenko, J. Am. Chem. Soc., 2016, 138, 14202-14205.

72 P. O. Anikeeva, J. E. Halpert, M. G. Bawendi and V. Bulović, Nano Lett., 2007, 7, 2196-2200.

73 M. Yang, N. Wang, S. Zhang, W. Zou, Y. He, Y. Wei, M. Xu, J. Wang and W. Huang, J. Phys. Chem. Lett., 2018, 9, 2038-2042.

74 Y. Shirasaki, G. J. Supran, W. A. Tisdale and V. Bulović, Phys. Rev. Lett., 2013, 110, 217403.

75 Z. Shi, Y. Li, S. Li, X. Li, D. Wu, T. Xu, Y. Tian, Y. Chen, Y. Zhang and B. Zhang, Adv. Funct. Mater., 2018, 28, 1707031.

76 Z. Shi, Y. Li, Y. Zhang, Y. Chen, X. Li, D. Wu, T. Xu, C. Shan and G. Du, Nano Lett., 2017, 17, 313-321. 